\title{
Hymenoptera Venom Allergy: Management of Children and Adults in Clinical Practice
}

\author{
Bilò $\mathrm{MB}^{1}$, Pravettoni $\mathrm{V}^{2}$, Bignardi $\mathrm{D}^{3}$, Bonadonna $\mathrm{P}^{4}$, Mauro $\mathrm{M}^{5}$, Novembre $\mathrm{E}^{6}$, Quercia $\mathrm{O}^{7}$, Cilia $\mathrm{M}^{8}$, \\ Cortellini $\mathrm{G}^{9}$, Costantino $\mathrm{MT}^{10}$, Cremonte $\mathrm{L}^{11}$, Lodi Rizzini $\mathrm{F}^{12}$, Macchia $\mathrm{L}^{13}$, Marengo $\mathrm{F}^{14}$, Murzilli $\mathrm{F}^{15}$, \\ Patella $\mathrm{V}^{16}$, Reccardini $\mathrm{F}^{17}$, Ricciardi $\mathrm{L}^{18}$, Ridolo $\mathrm{E}^{19}$, Romano $\mathrm{A}^{20}$, Savi $\mathrm{E}^{21}$, Schiavino $\mathrm{D}^{22}$, Severino $\mathrm{M}^{23}$, \\ Pastorello $\mathrm{EA}^{24}$
}

'U.O.C. Allergology, Department of Internal Medicine, University-Hospital Ospedali Riuniti di Ancona, Italy

${ }^{2}$ U.O.C. General Medicine - Immunology and Allergology, Foundation IRCCS Ca' Granda Ospedale Maggiore Policlinico, Milan, Italy

${ }^{3}$ U.O.C. Allergology, Ospedale Policlinico San Martino, Genova, Italy

${ }^{4}$ U.S.D. Allergology, Integrated University-Hospital of Verona, Italy

${ }^{5}$ U.O.S. Allergology, Hospital S. Anna Como ASST Lariana, Italy

${ }^{6}$ Complex Organizational Unit of Allergology, University-Hospital A. Meyer, Firenze, Italy

${ }^{7}$ High Specialization Unit of Allergology, Hospital of Faenza, AUSL (Local Health Unit) of Romagna, Italy

${ }^{8}$ Allergology Practice, C.d.S. of Scilla, Reggio Calabria, Italy

${ }^{9}$ Allergology, O.U. Internal Medicine and Rheumatology, Rimini, Local Health Unit of Romagna, Italy

${ }^{10}$ Departmental Structure Day Hospital Center, Allergology and Clinic Immunology Local Health Unit of Mantova, Intercompany Allergology ATS

Val Padana, Italy

${ }^{11 S S}$ Allergologia ASL AL Alessandria, Italy

${ }^{12}$ S.S.V.D. Allergology Civil Hospitals of Brescia, Department of Clinical and Experimental Sciences University of Brescia, Italy

${ }^{13}$ School and Chair of Allergology and Clinical Immunology, University of Bari, Italy

${ }^{14}$ Allergology and Clinical Immunology, A.O.U. Città della Salute e della Scienza di Torino

${ }^{15}$ U.O.S.D. of Allergology Hospital S.S. Filippo and Nicola, Avezzano (AQ), Italy

${ }^{16}$ Allergy and Clinical Immunology Division, Department of Medicine, Civil Hospital of Battipaglia, Salerno, Italy

${ }^{17}$ SOC Pneumology, Respiratory Physiopathology, integrated University Health Authority of Udine, Italy

${ }^{18}$ Allergy and Clinical Immunology Unit - University Hospital AOU Policlinico G.Martino, Department of Clinical and Experimental Medicine,

University of Messina, Messina, Italy

${ }^{19}$ Department of Medicine and Surgery, University of Parma, Italy

${ }^{20}$ Unit of Allergology, Presidio Columbus, Rome, Italy

${ }^{21}$ Operating Departmental Unit of Allergology, Hospital G. Da Saliceto, Piacenza, Italy

${ }^{22}$ Complex Operating Unit of Allergology, Policlinico Gemelli - School of Specialization in Allergology and Clinical Immunology, Catholic

University, Rome, Italy

${ }^{23}$ Allergy Unit, San Giovanni di Dio Hospital, Florence, Italy

${ }^{24}$ Complex Unit of Allergology and Immunology at ASST Grande Ospedale Metropolitano Niguarda - School of Specialization in Allergology and

Clinical Immunology at University of Milan, Italy

J Investig Allergol Clin Immunol 2019; Vol. 29(3): 180-205

doi: $10.18176 /$ jiaci.0310

\section{Abstract}

Hymenoptera venom allergy is an epidemiologically underestimated condition and a major cause of morbidity worldwide. Preventing future allergic reactions in patients who experience a systemic reaction is based on the correct management of the emergency followed by an accurate diagnosis, prescription of adrenaline autoinjectors, and, where indicated, specific venom immunotherapy. Some epidemiological studies highlight our poor knowledge of this disease and the frequent inadequacy of its management. Moreover, they emphasize the importance of such a life-saving treatment as specific immunotherapy. The availability of high-quality hymenoptera venom extracts for diagnostic and therapeutic use has dramatically improved the prognosis and quality of life of allergic patients. Subcutaneous venom immunotherapy is currently the most effective form of allergen-based immunotherapy, with a carry-over effect lasting up to several years after its interruption. This report on the management of hymenoptera venom-allergic children and adults was prepared by a panel of Italian experts. The main objective of this consensus document is to review the scientific evidence related to diagnosis, therapy, and management of patients allergic to hymenoptera venom. Thus, we can improve our knowledge of the disease and promote good clinical practices. The present document provides practical suggestions for correct diagnosis, prescription of emergency therapy and immunotherapy, and strategies for patient care.

Key words: Adults. Children. Diagnosis. Efficacy. Hymenoptera. Immunotherapy. Management. Safety. 


\section{Resumen}

La alergia al veneno de himenópteros es una condición subestimada epidemiológicamente que representa una causa importante de morbilidad en todo el mundo. La prevención de reacciones alérgicas futuras en pacientes que han desarrollado una reacción sistémica se basa en el manejo correcto de la emergencia, seguido de un diagnóstico correcto, la prescripción de autoinyectores de adrenalina y, en el caso de estar indicada, la prescripción de inmunoterapia específica con veneno (VIT). Varios estudios epidemiológicos destacan el escaso conocimiento de esta enfermedad y un frecuente tratamiento insuficiente. Además, enfatizan la importancia de la inmunoterapia específica, un tratamiento que puede salvar la vida del paciente. La disponibilidad de extractos de veneno de himenóptera de alta calidad para uso diagnóstico y terapéutico ha mejorado drásticamente el pronóstico y la calidad de vida de estos enfermos. La VIT subcutánea representa la forma más efectiva de inmunoterapia con alérgeno actualmente disponible, con una eficacia persistente que dura hasta varios años después de su interrupción. Este consenso sobre la evaluación clínica tanto de niños como de adultos alérgicos al veneno de himenópteros ha sido elaborado por un panel de expertos italianos. Su objetivo principal es revisar la evidencia científica disponible en el diagnóstico, la terapia y la evaluación clínica de los pacientes alérgicos al veneno de himenópteros con el propósito de mejorar el conocimiento sobre esta enfermedad y promover buenas prácticas clínicas. Se incluyen sugerencias prácticas para un diagnóstico correcto, la prescripción de terapia de emergencia e inmunoterapia, así como estrategias para el manejo de los pacientes.

Palabras clave: Adultos. Niños. Diagnóstico. Eficacia. Himenópteros. Inmunoterapia. Tratamiento. Seguridad.

\section{Introduction}

Hymenoptera venom allergy is an epidemiologically underestimated condition and a major cause of morbidity worldwide. Mortality is low, although underestimates are common, with many sting fatalities being misdiagnosed. Preventing future allergic reactions in patients who have developed a systemic reaction is based on correct management of the emergency followed by diagnosis, prescription of adrenaline autoinjectors, and, where indicated, specific venom immunotherapy (VIT). Some epidemiological studies highlight our poor knowledge of this disease and the frequent inadequacy of its management [1] and emphasize the importance of such an important life-saving treatment as specific immunotherapy.

The availability of high-quality hymenoptera venom extracts for diagnosis and therapy has dramatically improved the prognosis and quality of life of allergic patients. Subcutaneous VIT is currently the most effective form of allergen-based immunotherapy, with a carry-over effect lasting up to several years after its interruption.

This report on the management of hymenoptera venom allergy was prepared by a panel of Italian experts.

\section{Objectives and Work Methodology}

The main objective of this consensus is to review scientific evidence associated with the diagnosis, treatment, and management of patients who are allergic to hymenoptera venom and thus to improve our knowledge of this disease and promote good clinical practice. This document provides practical suggestions for correct diagnosis, prescription of emergency therapy and immunotherapy, and strategies for the care of patients.

The data on the various topics addressed in this report were obtained from studies published in English and Italian and collected by searching the MEDLINE and EMBASE databases. The GRADE system was used for translating research results into recommendations based on scientific evidence (Table 1) [2].
We included all recommendations for which agreement was by $\geq 90 \%$ of the authors. The panel of experts comprised physicians with broad experience in hymenoptera venom allergy working in one of the main allergy centers. Some centers started administering VIT in the early 1980s.

\section{Hymenoptera Venom Allergy: Epidemiology and Clinical Picture}

\section{Hymenoptera}

The insects of the order of Hymenoptera comprise aculeate species whose venom can trigger allergic reactions in humans. These reactions range from relatively mild reactions to fatal anaphylaxis [3]. In Europe, hymenoptera causing allergic reactions belong to the Apidae and Vespidae families or, sporadically, to Formicidae (Formica rufa) [4] and Myrmicinae (Solenopsis invicta) [5], which are widespread in North and Central America and in Australia.

The Apidae family includes the subfamilies Apinae (Apis mellifera) and Bombinae (Bombus terrestris, agrarum, medics), while the Vespidae family is composed of the Vespinae subfamily, including the genera Vespula (germanica, vulgaris), Dolichovespula (maculata, arenaria, saxonica, media), and Vespa (crabro, orientalis velutina var nigrithorax) and the subfamily Polistinae, which includes the genus Polistes (dominula, gallicus).

The bees and vespids of the genus Vespula are widespread in the far northern regions of Europe. In southern Europe, in addition to Vespula, hornets are a frequent cause of allergic reactions (genus Vespa), including the most widespread species Vespa crabro and some species of Polistes, such as Polistes dominula [6]. The genus Dolichovespula has a more limited diffusion and can be considered similar to Vespula from an allergological point of view.

In 2005, Vespa velutina nigrithorax, which is from Southeast Asia, was detected in the South of France. Vespa velutina is a predator of bees and is rapidly spreading from 
Table 1. Levels of Evidence and Grade of Recommendation [2]

\begin{tabular}{ll}
\hline Level of Evidence \\
\hline Level I & $\begin{array}{l}\text { Systematic reviews, meta-analysis, } \\
\text { randomized control trials }\end{array}$ \\
Level II & $\begin{array}{l}\text { Two groups, nonrandomized studies } \\
\text { (eg, cohort, case-control) }\end{array}$ \\
Level III & $\begin{array}{l}\text { One group nonrandomized } \\
\text { (eg, before and after, pretest and posttest })\end{array}$ \\
Level IV & $\begin{array}{l}\text { Descriptive studies that include analysis } \\
\text { of outcomes (single-subject design, case series) }\end{array}$ \\
Level V & $\begin{array}{l}\text { Case reports and expert opinion that include } \\
\text { narrative literature, reviews, and consensus } \\
\text { statements }\end{array}$ \\
\hline
\end{tabular}

Grade of Recommendation

Grade A Consistent level I studies

Grade B Consistent level II or III studies or extrapolations from level I studies

Grade C Level IV studies or extrapolations from level II or III studies

Grade D Level V evidence or troublingly inconsistent or inconclusive studies at any level

France to neighboring countries. Anaphylactic reactions have been reported after Vespa velutina stings, with a variable degree of cross-reactivity with other vespids [7].

Given its low aggressiveness, allergy to bumblebees concerns a limited number of persons, in particular professionally exposed individuals [8], and should therefore be investigated on the basis of a detailed clinical history, provided that a suitable extract is commercially available for diagnosis. Immunotherapy with honeybee venom alone may be sufficient in non-professionally exposed bumblebee-allergic patients with primary sensitization to bee venom, whose reaction is most likely due to cross-reactivity. In occupationally exposed patients, who are frequently stung by bumblebees, immunotherapy should be with purified bumblebee venom (when available) [9].

Although difficult, recognition of the stinging insect remains crucial in the management of allergic reactions and is an integral part of the diagnosis in that it helps us to select specific immunotherapy; thus, information on the behavior and morphological characteristics of the culprit insects make for an accurate clinical history and diagnosis.

A mellifera has a characteristic serrated sting which remains stuck in the tissue together with the venom sack. The bee dies by self-evisceration when flying away from the victim. The vespids and other apids (bumblebees), on the other hand, have smooth stings, which can be extracted from their victims, thus enabling them to sting several times consecutively.

\section{Epidemiology}

Depending on the living environment and type of activity, $56 \%-94 \%$ of the adult population are estimated to have been stung by a hymenoptera insect at least once in their lifetime; in Europe, this is by a bee in about one-third of cases [10]. As a consequence, the development of specific IgE to 1 or more venom allergens can occur as an ancestral defense response against the toxic effects of venom [11]. Such a response may be favored by atopic diathesis and genetic factors and may correlate with a high level of total $\operatorname{IgE}[10,12]$.

The prevalence of asymptomatic sensitization is estimated to range from $9.3 \%$ to $40.7 \%$ in the adult population, with higher proportions in cases of high exposure, for example, beekeepers $(30 \%-60 \%)[13,14]$.

Epidemiological studies report wide variability in the prevalence of allergic reactions: repeated exposure to stings (studies on beekeepers) increases the prevalence of a large local reaction (LLR) by as much as 38\% [15] and that of systemic reactions by $30 \%-45 \%[16,17]$.

In Europe, the prevalence of systemic reactions in the adult general population is $0.3 \%-8.9 \%[10,18]$, which increases to 14\%-32\% among beekeepers [13]. Taking into account studies on anaphylaxis as a whole, hymenoptera stings are responsible for $7.3 \%-59 \%$ of cases, depending on the populations investigated, and are more frequent in adults [15].

According to data from the European Anaphylaxis Registry, out of 3333 diagnosed cases, hymenoptera venom allergy was the most frequent cause of severe reactions in the adult population (48.2\%) [19].

Data from emergency departments in several parts of the world show that hymenoptera venom allergy is responsible for $1.5 \%-34 \%$ of anaphylactic reactions, with the lowest prevalence recorded in urban hospitals [10].

Recent Italian studies on cases of anaphylaxis reported directly by emergency departments to allergy centers for diagnostic assessment have shown that hymenoptera venom allergy is the most frequent cause (42\%-70\% of cases) [20,21].

Hymenoptera venom allergy is responsible for about $20 \%$ of the total cases of fatal anaphylaxis in several countries [10]. Death is due to shock with multiple organ failure within 10-15 minutes of the sting and, in a quarter of cases, edema of the glottis [22].

Overall, the incidence of mortality in various European countries is between $0.03 /$ million/year in Italy and 0.48 in France. In Italy, ISTAT data for the period 1994-2003 show 94 deaths [15]. Mortality data are generally underestimated, as deaths are likely to be attributed by mistake to other causes, in particular cardiac disorders [10].

Since $40 \%$ of cases of fatal anaphylaxis occur as a first reaction to hymenoptera venom, it is important to carefully evaluate the risk factors that may cause a transition from asymptomatic sensitization to a more severe clinical manifestation [10,23-26].

\section{Clinical Aspects}

Hymenoptera venom is a mixture of various components, including bioactive molecules such as histamine, serotonin, tyramine, catecholamines, low-molecular-weight peptides (including mastoparans, kinins, and chemotactic peptides), and high-molecular-weight proteins (including phospholipase, hyaluronidase, mellitin, antigen 5), which differ by species and can act as allergens and, in some cases, cause toxic reactions. 
From a clinical point of view, we can distinguish between local reactions, LLRs, systemic allergic reactions, toxic systemic reactions, and unusual reactions.

In most cases, local reactions consist of itching, erythema, and edema of limited extension; they are transient, normal consequences of the vasoactive and inflammatory action of some venom components. In the event of allergy, more severe large local reactions may occur, and these are characterized by delayed and prolonged inflammation and edema increasing within 24-48 hours and resolving in 3-10 days, with an average extension exceeding $10 \mathrm{~cm}$ in diameter.

The anaphylaxis guidelines of the World Allergy Organization [27] and of the European Academy of Allergy and Clinical Immunology (EAACI) [28] have established clinical criteria for the diagnosis of anaphylaxis, confirming the proposal of the second symposium on the definition and management of anaphylaxis summary report - Second National Institute of Allergy and Infectious Disease/Food Allergy and Anaphylaxis Network Symposium [29].

Various classifications of the grade of severity of reactions have been proposed, those of Mueller [30] and Ring and Messmer [31] being the most frequently referred to. Both classifications have limitations: that of Mueller does not take into account the possible absence of cutaneous symptoms and the possibility that an isolated cardiovascular shock might be the only allergic sting-induced manifestation [29], while that of Ring and Messmer is almost entirely focused on cardiovascular collapse, which is considered more severe than respiratory impairment.

The classification of mild, moderate, and severe reactions of Brown [32] can also be adapted to systemic allergic reactions to hymenoptera venom [33]. EAACI recently proposed a simplification of the severity criteria for acute allergic reactions, dividing them into local (grade 1) and systemic (grades 2 and 3) [34].

Skin symptoms are the most frequent manifestation (80\%) and represent the only manifestation in $15 \%$ of cases of systemic reactions in adults. Some cases are characterized by onset of chronic urticaria and cold urticaria after the sting, generally without an immediate reaction and with an unknown risk for systemic reactions to re-sting. Almost $50 \%$ of systemic reactions include respiratory symptoms (upper airway angioedema). Symptoms and signs of hypotension may appear in over $60 \%$ of adults; in half of the cases, these occur with loss of consciousness. Cardiac involvement during anaphylaxis can cause bradycardia, arrhythmias, and acute coronary syndromes, thus making it compatible with Kounis syndrome $[35,36]$. It can also be secondary to decreased venous return, which is in turn due to histamine-induced vasodilatation, and permeabilization. Gastrointestinal symptoms (abdominal pain, nausea, vomiting, and diarrhea) and uterine cramps with possible miscarriage may occur, as may neurological symptoms (eg, convulsions). Biphasic anaphylaxis, which is characterized by recurrence of anaphylactic symptoms within 4-12 (exceptionally 72) hours [37] after resolution (without re-exposure), was reported in $0.4 \%-14.7 \%$ of cases [38].

Toxic systemic reactions are caused by the action of venom components with enzymatic activity and organ-specific toxicity and usually occur after multiple simultaneous stings (from several tens to several hundreds). Toxic effects occur in hours to days and consist of rhabdomyolysis, intravascular hemolysis, coagulation disorders, liver damage, and acute renal failure. Fatal cases are uncommon [39].

Unusual reactions are rare and are caused by a toxic or non-IgE-mediated immunological mechanism, in some cases by autoimmunity. These can occur within hours to days of a single sting and include serum sickness-like manifestations, central nervous system manifestations (acute encephalopathy, Guillain-Barré syndrome, myasthenia, peripheral neuritis), hematological reactions (thrombocytopenic purpura, HenochSchönlein purpura, hemolysis, coagulation disorders), muscle reactions (rhabdomyolysis), renal reactions (acute renal failure due to interstitial nephritis or tubular damage, nephrotic syndrome), and respiratory reactions (alveolar hemorrhage) [40]. Metrorrhagia after a bee sting is unusual [41].

\section{Pediatric Aspects}

The prevalence of asymptomatic sensitization was reported to be $3.7 \%$ in an Italian pediatric case study [42]. The prevalence of LLRs has been reported to be between $0.9 \%$ [43] and $20.8 \%$ [44]; the prevalence of systemic reactions is below $1 \%[15,42]$.

According to the European Anaphylaxis Registry, hymenoptera venom allergy is the second cause of severe reactions in children $(20.2 \%)$ after food allergy [19].

Risk factors for severe systemic reactions after hymenoptera stings in children were evaluated by Graif et al [45] in a population of adolescents aged 13-14 years. Atopic children had a significantly higher rate of severe reactions than nonatopic children (36.9\% vs $24.8 \%$ ). Therefore asthma, allergic rhinitis, and atopic eczema should be considered risk factors for reactions of any severity; moreover, the severity of the reaction is also associated with the severity of asthma. Atopy was confirmed as a risk factor for severe reactions in a more recent study [46]. However, this finding should be confirmed in larger pediatric populations.

In children, systemic reactions mostly affect the skin and rarely the cardiovascular system. Skin symptoms are the only clinical manifestation in $60 \%$ of cases [47].

Children have a favorable prognosis regarding re-sting, both in studies based on sting challenge [48] and field sting [49,50].

\section{Treatment of Acute Reactions}

\section{In the Hospital Setting}

Treatment of anaphylactic reactions in the hospital setting should adhere as closely as possible to guidelines. After discharge, the patient should be referred to an allergy specialist and prescribed adrenaline autoinjectors [51-53]. As for postanaphylaxis monitoring, WAO guidelines indicate a minimum of 8-10 hours to cover the risk of late anaphylactic reactions [27]. American guidelines [54] suggest individualizing this period, whereas the EAACI guidelines [28] advise a minimum duration of 6-8 hours for patients with respiratory symptoms and 12-24 hours in the event of hypotension or collapse.

The expert panel believe that, after appropriate therapy and complete resolution of the clinical picture, the patient should 
be kept under observation and monitored for at least 6-8 hours up to 24 hours depending on the severity and characteristics of the reaction at onset, comorbidity, and risk factors (strength of recommendation, D). The duration of this period may depend on the internal regulations of the individual hospital.

Management of anaphylaxis in the hospital setting requires general measures and the administration of specific medicinal products [27].

General measures include the following: $(a)$ Monitoring of vital parameters. (b) Positioning of the patient in the Trendelenburg position (supine with legs raised $10^{\circ}-15^{\circ}$ ) or, in the case of vomiting, on the right side. If the patient is pregnant, she should be placed in the supine position to gently dislodge the fetus to the left so as to decompress the inferior vena cava and thus improve venous return to the heart; if she is laid on one side, it should be the left. (c) Rapid cannulation of a peripheral venous access with a high-gauge needle (at least $18 \mathrm{G})$. (d) Rapid intravenous administration of isotonic saline solution (plasma expanders should be avoided owing to the risk of mast cell degranulation). (e) Administration of oxygen (if necessary); in the case of pregnancy, oxygen should be administered to avoid fetal hypoxemia ( $4 \mathrm{~L} / \mathrm{min}$ using nasal prongs). ( $f$ ) Continuous clinical and instrumental monitoring of the patient (arterial blood pressure, heart rate [bradycardia in hypotension seems to have a negative prognostic value], and peripheral oxygen saturation).

The specific medicinal products used in the management of anaphylaxis are as follows:

- Adrenaline: Adrenaline is the treatment of choice for anaphylaxis regardless of the presence of shock (strength of recommendation, C) [27-29,55,56]. It slows the progression of symptoms and can prevent the development of fatal or biphasic reactions (strength of recommendation, C) $[57,58]$. If the correct dosage is administered, it can be used without absolute contraindications in pediatric and geriatric populations and in patients with heart disease $[28,59,60]$, except for some conditions, such as long QT syndrome (in this case, adrenaline should be administered with extreme caution, in the case of real need, and in the presence of the cardiologist).

Adrenaline is also the drug of choice for the treatment of anaphylaxis in pregnant women (strength of recommendation, D) [61-63]; in fact, ephedrine may have a lower risk of uterine contractions, although if it proves inefficacious, it may cause escalation of the anaphylactic reaction, with the consequent risks.

Adrenaline should be administered intramuscularly in the lateral thigh (vastus lateralis muscle) at a dose of $0.01 \mathrm{mg} / \mathrm{kg}$ of a $1 / 1000$ solution, with a maximum dose of $0.3 \mathrm{mg}$ in children and $0.5 \mathrm{mg}$ in adults [27]. The dose may be repeated after 5-15 minutes if necessary (strength of recommendation, B) [27,59].

Intravenous administration should be reserved for the most severe cases, with imminent danger of life for cardiovascular collapse (strength of recommendation, D) $[56,64]$. The infusion should be stopped 30 minutes after clinical stabilization. Table 2 describes the modalities and the concentrations of intravenous adrenaline.
Table 2. Intravenous Administration of Adrenaline

\section{Bolus}

1 ampoule diluted to $10 \mathrm{~mL}(100 \mu \mathrm{g} / \mathrm{mL}) \rightarrow 0.5 \mathrm{~mL}(=50 \mu \mathrm{g})$ in bolus or syringe pump

1 ampoule diluted to $50 \mathrm{~mL}(20 \mu \mathrm{g} / \mathrm{mL}) \rightarrow 180 \mathrm{~mL} /$ hour for 1 minute

Infusion in syringe pump

1 ampoule of $1 \mathrm{mg}$, diluted to $50 \mathrm{~mL}$ with saline solution speed $=20 \mu \mathrm{g} / \mathrm{mL}$

Infusion rate in syringe pump:

$\begin{array}{ll}5 \mu \mathrm{g} / \mathrm{min} & 15 \mathrm{~mL} / \mathrm{h} \\ 10 \mu \mathrm{g} / \mathrm{min} & 30 \mathrm{~mL} / \mathrm{h} \\ 15 \mu \mathrm{g} / \mathrm{min} & 45 \mathrm{~mL} / \mathrm{h}\end{array}$

Table 3. Dopamine: Hourly Rate of Administration Based on Body Weight and Desired Dosage ${ }^{\text {a }}$

\begin{tabular}{lcccccc}
\hline Body & \multicolumn{2}{c}{$5 \mu \mathrm{g} / \mathrm{kg} / \mathrm{min}$} & \multicolumn{2}{c}{$10 \mu \mathrm{g} / \mathrm{kg} / \mathrm{min}$} & \multicolumn{2}{c}{$15 \mu \mathrm{g} / \mathrm{kg} / \mathrm{min}$} \\
& $\mu \mathrm{g} / \mathrm{min}$ & $\mathrm{mL} / \mathrm{h}$ & $\mu \mathrm{g} / \mathrm{min}$ & $\mathrm{mL} / \mathrm{h}$ & $\mu \mathrm{g} / \mathrm{min}$ & $\mathrm{mL} / \mathrm{h}$ \\
\hline 40 & 200 & 1.50 & 400 & 3.00 & 600 & 4.50 \\
50 & 250 & 1.87 & 500 & 3.75 & 750 & 5.62 \\
60 & 300 & 2.25 & 600 & 4.50 & 900 & 6.75 \\
70 & 350 & 2.62 & 700 & 5.25 & 1050 & 7.87 \\
80 & 400 & 3.00 & 800 & 6.00 & 1200 & 9.00 \\
90 & 450 & 3.37 & 900 & 6.67 & 1350 & 10.12 \\
\hline
\end{tabular}

a200-mg ampoule: 2 ampoules in 5\% glucose solution administered using a $50-\mathrm{mL}$ syringe pump $(=8000 \mu \mathrm{g} / \mathrm{mL})$.

- Dopamine: Dopamine should be used if it is not possible to maintain stable circulatory function with adrenaline. The dosage is $5-15 \mu \mathrm{g} / \mathrm{kg} / \mathrm{min}$. Table 3 shows the hourly infusion rate using a syringe pump for the desired dosages based on body weight.

- Antihistamines: The use of anti- $\mathrm{H}_{1}$ is recommended only for the treatment of skin symptoms (strength of recommendation, B) $[28,65,66]$. There are no controlled studies to support the use of antihistamines for the treatment of anaphylaxis [67]. Intravenous administration has the advantage of acting more quickly, although it should be performed very slowly to avoid adverse effects (including hypotension). The suggested dose is generally $10 \mathrm{mg}$ of chlorpheniramine in adults and 2.5-5 $\mathrm{mg}$ in children [27].

The concomitant administration of anti- $\mathrm{H}_{2}$ antihistamines has not proved to have greater therapeutic efficacy and is therefore not recommended in guidelines.

- Corticosteroids: Corticosteroids are used for the control of bronchospasm and prevention of biphasic reactions $[28,54,59,65]$, even if there are no controlled studies to confirm their effectiveness in the treatment of acute anaphylactic reaction (strength of recommendation, D) [68]. The recommended drugs are intravenous hydrocortisone $200 \mathrm{mg}$ in adults (in children up to $100 \mathrm{mg}$ ) or intravenous methylprednisolone 
Table 4. Doses of Glucagon to Be Administered During Anaphylaxis

\begin{tabular}{ll}
\hline Glucagon Dosage & Syringe Pump Infusion Speed \\
\hline $1 \mathrm{mg} / \mathrm{h}$ & $50 \mathrm{~mL} / \mathrm{h}$ \\
$2 \mathrm{mg} / \mathrm{h}$ & $100 \mathrm{~mL} / \mathrm{h}$ \\
$3 \mathrm{mg} / \mathrm{h}$ & $150 \mathrm{~mL} / \mathrm{h}$ \\
$4 \mathrm{mg} / \mathrm{h}$ & $200 \mathrm{~mL} / \mathrm{h}$ \\
$5 \mathrm{mg} / \mathrm{h}$ & $250 \mathrm{~mL} / \mathrm{h}$ \\
\end{tabular}

1-mg ampoule, diluted to $50 \mathrm{~mL}$ with saline solution $=0.02 \mathrm{mg} / \mathrm{mL}$.

$50-100 \mathrm{mg}$ in adults (in children $1 \mathrm{mg} / \mathrm{kg}$, maximum $50 \mathrm{mg}$ ) [27].

- Glucagon: Glucagon exerts both positive inotropic and chronotropic effects for activation of adenylyl cyclase activity independently of the $\beta$ receptor. It is sometimes needed in patients taking a $\beta$-adrenergic blocker who have hypotension and bradycardia and who do not respond optimally to adrenaline. Glucagon can be administered intravenously in adult patients at a dose of $1 \mathrm{mg}$ as an initial intravenous bolus; the dose can be repeated every 5 minutes and increased to $3-5 \mathrm{mg}$ if necessary. Continuous infusion in a syringe pump should be at $1-5 \mathrm{mg} / \mathrm{h}$ (strength of recommendation, D) (Table 4). It should be pointed out that glucagon is an off-label drug for the therapy of anaphylaxis and can lead to severe vomiting and hyperglycemia $[69,70]$.

- Desmopressin: Desmopressin can be used for the treatment of anaphylactic shock that is unresponsive to adrenaline (strength of recommendation, D) [71,72].

- Bronchodilators: Inhaled short-acting formulations (eg, salbutamol) are preferred.

\section{Self-treatment}

All patients with a history of anaphylactic reaction should be provided with adrenaline autoinjectors to be injected into the vastus lateralis muscle $[27,28,73]$. Currently available autoinjectors differ from country to country [74]. In obese or overweight patients, the reduced length of the needle does not always ensure intramuscular administration $[75,76]$; therefore, the patient should be advised to press the autoinjector well into the thigh fat to compress it and allow the adrenaline to penetrate the muscle.

One study compared 3 adrenaline autoinjectors for penetration depth in ballistic gelatin, namely, 2 cartridgebased devices (EpiPen and Jext) and 1 syringe-based device (Anapen) [77]. For the 2 cartridge-based systems, the mean (SD) maximum injection depth in gelatin within 10 seconds was 29.68 (2.08) $\mathrm{mm}$ for EpiPen and 28.87 (0.73) $\mathrm{mm}$ for Jext; for the syringe-based system (Anapen), the depth was $18.74(1.25) \mathrm{mm}$. Cartridge-based systems therefore reached a depth that was double the length of the needle. The same study also showed that the average depth of the adipose tissue in 50 females was $14.8 \mathrm{~mm}$. Comparison of the robustness and performance of these 3 devices revealed that cartridgebased systems are more robust and ensure greater speed, validity, correctness of the dose, and accuracy of the site of administration than the syringe-based system. However, a recent study showed that the bioavailability of adrenaline administered using a syringe-based autoinjector is not affected by needle length [78].

In the pediatric population, considering the fixed dosages of the autoinjector, there is a risk of administering a lower or higher dose, depending on body weight [59,79]. In children weighing $15-30 \mathrm{~kg}$, a lower dose should be used if the anaphylactic reaction is not severe; an adult dose should be administered if the anaphylaxis is severe or the patient has concomitant bronchial asthma (risk factor for fatal anaphylaxis) [80].

Table 5 shows the symptoms and signs indicative of an anaphylactic reaction to ensure that the patient knows when to administer adrenaline; this table can be provided to the patient during training with the device.

Table 5. Criteria for the Diagnosis of Anaphylaxis [27]

Naive patient

Acute onset (minutes or hours) of cutaneous and/or mucosal symptoms (pruritus, flushing, lips-tongue-uvula swollen, hives and generalized urticaria)

One or more of the following:

A. Respiratory symptoms (dyspnea, wheezing, bronchoconstriction, stridor, reduced peak expiratory flow, hypoxemia)

B. Decreased blood pressure and/or associated symptoms of the target organs (hypotonia, collapse, syncope, incontinence)

These criteria allow the diagnosis of about $80 \%$ of cases of anaphylaxis, as cutaneous symptoms are present in $80 \%$ of anaphylactic reactions

After exposure to a likely allergen

Two or more of the following:

A. Cutaneous and/or mucosal symptoms (pruritus, flushing, lips-tongue-uvula swollen, hives and generalized urticaria)

B. Respiratory symptoms (dyspnea, wheezing, bronchoconstriction, stridor, reduced peak expiratory flow, hypoxemia)

C. Decreased blood pressure and/or associated symptoms of the target organs (hypotonia, collapse, syncope, incontinence)

D. Persistent gastrointestinal symptoms (abdominal pain, cramps, vomiting)

After exposure to a known allergen

Reduction in blood pressure:

A. Infants and children:

$<70 \mathrm{mmHg}$ from $1 \mathrm{mo}$ to $1 \mathrm{y}$

$<70 \mathrm{mmHg}(+2 \times \mathrm{y})$ from 1 to $10 \mathrm{y}$

$<90 \mathrm{mmHg}$ from 11 to $17 \mathrm{y}$

B. Adults:

$<90 \mathrm{mmHg}$ or a decrease $>30 \%$ from baseline values 
Although many patients are afraid to use their adrenaline autoinjector for fear of adverse effects [81], no significant adverse effects have been reported, with the exception of the known onset of tachycardia, tremors, and peripheral vasoconstriction [82].

Even if adrenaline remains the first-choice drug in anaphylactic reactions, the patient with mild systemic reactions (eg, only hives) may also self-treat with oral corticosteroids (eg, methylprednisolone tablets $16 \mathrm{mg}=4$ tablets) and a double dose of second-generation antihistamines.

\section{Indications for the Prescription of Adrenaline Autoinjectors}

Adrenaline autoinjectors should be prescribed to the following groups of patients $[28,33,73,74]$ :

- Children and adults with systemic reactions more severe than systemic skin reaction or with a high risk of reexposure to stings (eg, beekeepers), before VIT (level of evidence IV, strength of recommendation $\mathrm{C}$ ).

- Children and adults undergoing VIT, but with risk factors for incomplete clinical protection (very severe onset reaction, adverse reactions during immunotherapy, lack of sting protection during VIT, bee venom allergy) (level of evidence $\mathrm{V}$, strength of recommendation D).

- Children and adults who have discontinued VIT but present risk factors for incomplete clinical protection (eg, particularly severe pre-VIT systemic reaction, systemic reaction caused by VIT, lack of protection during VIT) (level of evidence $\mathrm{V}$, strength of recommendation D).

- Children and adults with elevated levels of serum mast cell tryptase or mast cell disorders and a history of systemic reaction to hymenoptera sting, independently of VIT (level of evidence IV, strength of recommendation D).

- Children and adults who discontinued VIT, despite having mast cell disorders and/or elevated levels of serum mast cell tryptase (level of evidence IV, strength of recommendation $\mathrm{C}$ ).

According to European guidelines, the prescription of 2 adrenaline autoinjectors is recommended in patients with mast cell disorders and/or elevated levels of serum mast cell tryptase, and in patients with a history of very severe anaphylactic reactions who required the administration of multiple doses of adrenaline or who do not have rapid access to hospitals [28]. Based on currently available data [83], the expert panel considers basal tryptase levels above $7.95 \mu \mathrm{g} / \mathrm{L}$ as high in those patients with a history of anaphylactic reaction caused by hymenoptera sting with loss of consciousness and no cutaneous/mucosal involvement.

The expert panel also suggests prescribing 2 adrenaline devices to obese patients, as the injection might not reach the muscle and could therefore prove less effective.

Regarding LLRs, the risk of a systemic reaction is not currently considered so high as to require the prescription of adrenaline [74]. Nevertheless, Italian experts do not rule out the possibility of prescribing adrenaline to patients at risk of multiple stings (eg, beekeepers) and to those who had a single LLR, since in these patients the risk of a subsequent systemic reaction to a re-sting cannot be completely excluded compared with patients who have already experienced repeated LLRs $[84,85]$.

\section{European Medicines Agency Provisions on Adrenaline Autoinjectors}

After evaluation of all available data, the European Medicines Agency (EMA) confirmed that intramuscular administration is the most indicated route for obtaining a rapid response in the treatment of anaphylaxis [86].

The EMA observed that correct administration of adrenaline by autoinjectors is affected by several factors such as needle length, thickness of subcutaneous fat, mode of operation of the autoinjector (whether spring-loaded and/or cartridge-based), angle with which it is placed into the skin, force used to activate it, and the patient's ability to follow the instructions properly.

Healthcare professionals are recommended to prescribe 2 autoinjectors, which patients should be advised to carry with them at all times, and to instruct the patient on how to use the autoinjector through educational material and practical training.

\section{Diagnostic Criteria}

Diagnosis is based on the classification of the type of reaction, confirmation of IgE-mediated pathogenesis, and identification of the stinging insect. On this basis, the clinical history and the results of in vivo and in vitro tests are crucial $[3,87]$.

The history includes the description of the symptoms and of the course of the reaction (possibly documented by a medical report), the number of stings, the characteristics of the culprit insect (where possible), and the identification of specific risk factors for the severity of reaction [3].

It may be useful to show the patient an entomological notice board to facilitate the identification of the stinging insect; $73 \%$ of Vespula-allergic patients accurately identify this kind of hymenoptera on the board [88].

Since it is possible to document sensitization to venom in $10 \%-30 \%$ of patients with a negative history, only those with a history of previous systemic reaction $[3,33,87,89]$ should be investigated. Table 6 shows the indications for performance of diagnostic tests.

Table 6. Indications for Performing Diagnostic Tests

Indicated

- In patients with a history of systemic reaction following hymenoptera stings

Not indicated:

- In persons with a positive family history for allergic reaction to hymenoptera stings

- In persons who have an unjustified fear of developing a systemic reaction to hymenoptera stings following news of fatal anaphylaxis in the media

- As screening in the general population

Optional:

- In patients with a history of large local reactions 
In patients with a history of LLR, skin tests (as well as determination of specific $\operatorname{IgE}$ ) may be considered optional, at the discretion of the clinician in specific cases, for example in patients at a greater risk of re-sting with recurrent and bothersome LLRs (eg, beekeepers, farmers), who could benefit from immunotherapy [90].

Skin tests are the gold standard for diagnosis and should be carried out at least 2 weeks after the last sting to exclude a false-negative response during the refractory period $[3,33,87]$. As this period may be even longer, tests yielding negative results in persons with a suggestive history should be repeated after 1-2 months. Conversely, in some patients, sensitization can only be demonstrated during the first week after the reaction [91].

European guidelines suggest performing skin tests gradually, that is, prick tests first, followed, if negative, by intradermal tests $[3,33,87]$. Intradermal tests should be performed even in cases of a positive prick test result in order to correctly identify a cutaneous endpoint for follow-up of VIT. Correct performance of skin tests with hymenoptera venom is of crucial importance, both to ensure an accurate diagnosis and to monitor VIT [92]. In particular, intradermal tests should be carried out with $0.02 \mathrm{~mL}$ of the allergenic extract injected into the dermis to generate a wheal of approximately $3 \mathrm{~mm}$ in diameter. The reading should be performed after 15-20 minutes; a positive result is defined as an increase of at least $3 \mathrm{~mm}$ in the average diameter of the initial wheal, with associated erythema. A morphological score should be used to enable comparison of the results. This consists of drawing, on transparent cellophane, the area injected and the area of the reaction after 15-20 minutes [93].

The prick test is carried out at $100 \mu \mathrm{g} / \mathrm{mL}$. Intradermal testing can start from very low concentrations, according to the symptoms presented by the patient; concentrations ranging from 0.001 to $1 \mu \mathrm{g} / \mathrm{mL}$ are normally used.

The sensitivity of the prick test is lower than that of the intradermal test. In a study performed on 301 patients allergic to Vespula species venom, prick testing identified $49 \%$ of cases, while the combination of prick and intradermal reaction facilitated a diagnosis in $94 \%$ of cases [94]. Intradermal testing with nondialysate venoms can be irritating at concentrations higher than $1 \mu \mathrm{g} / \mathrm{mL}$ [95]. In Europe, standardized venoms of A mellifera, Vespula species, Polistes species, and V crabro are currently available; the venoms of Vespula and Polistes consist of a mix of clinically relevant species (Vespula species: $V$ vulgaris, $V$ flavopilosa, $V$ germanica, $V$ maculifrons, $V$ pennsylvania, and Vsquamosa; Polistes species [American]: $P$ annularis, $P$ exclamans, $P$ fuscatus, and $P$ metricus). Because of low cross-reactivity between European and American $P$ venoms [96], extracts of $P$ dominula are now available for both diagnosis and VIT [97]. On the other hand, high crossreactivity between Vespula species venom and $V$ crabro has been confirmed [98]. A recent study [99] suggested that, in patients with a proven reaction to V crabro, VIT with $V$ crabro venom may have a higher safety profile.

Skin tests with venoms are generally safe, even in patients with mastocytosis $[100,101]$. One study highlighted safety, even if the tests are carried out simultaneously at different concentrations [102]. The Italian expert panel considered that available data are insufficient and recommended a preliminary step where the same concentration of several venoms is simultaneously used for skin testing. A higher concentration should only be used after reading the reactions to the first set. This caution is to be maintained, especially in patients with severe anaphylactic reaction or mast cell disorders.

The total IgE dosage may help to ensure correct interpretation of specific $\mathrm{IgE}$ values, especially if they are very low [103]. In the event of very high levels, the presence of concomitant pollinosis should be investigated.

Serum specific IgE can be detected immediately after the sting, even if the best period for its determination is 1-4 weeks after the sting [3].

The sensitivity of serological tests using whole extracts is generally lower than that of skin tests. In general, in vitro tests for determination of specific IgE to the whole venom extract can be negative in up to $20 \%$ of patients with positive skin test results, whereas approximately $10 \%$ of patients with negative skin test results are positive in the in vitro test. Therefore, guidelines suggest performing both tests [3,33,87,104].

The sensitivity of serological tests for Vespula species is lower than that of tests for bee venom: $98 \%$ to $100 \%$ for bee $[105,106]$ and $83 \%$ to $97 \%$ for Vespula $[105,106]$. A new in vitro method enriched with the recombinant allergen Ves $\mathrm{v}$ proved more sensitive than traditional methods [94]. Furthermore, it has recently been hypothesized that negative skin test results with $A$ mellifera extract may be due to a minor presence or even absence of some allergens in diagnostic and therapeutic extracts [107]. It is to be noted that the values of serum specific IgE to $V$ crabro venom may vary according to the laboratory method used.

Diagnosis is complicated by sensitization to multiple venoms in patients who have not identified the stinging hymenopteran. The double positivity to venom of $A$ mellifera and Vespula species is found in $25 \%-40 \%$ of cases and may be due to double sensitization, cross-reactivity between epitopes present in both venoms (hyaluronidase; Api m 5 and Ves v 3; Api m 12 and Ves v 6), and cross-reactive carbohydrate determinants (CCDs). The commercial availability of some major allergens expressed in recombinant form enables implementation of component-resolved diagnosis (CRD) $[103,108]$.

Bee venom-allergic patients often have a broad sensitization profile. Api m 1, the most relevant allergen of bee venom, is not sensitizing in up to $43 \%$ of cases [109]. The combination of 2 allergens (Api $\mathrm{m} 1$ and 10) enables diagnosis in 86.8\% of cases; the combination of 6 allergens (Api m 1- 5, Api $\mathrm{m} 10$ ) has a sensitivity of $94.4 \%$ [109]. Currently marketed recombinant allergens include rApi m 1, rApi m 2, rApi m 3,

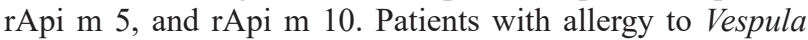
venom are sensitized mainly to Ves $v 1$ and Ves $v 5$. The combined search of specific IgE toward these 2 recombinant allergens enables the identification of $92 \%-94 \%$ of Vespulaallergic patients [110,111].

In Southern Europe, double Vespula-Polistes sensitization is more frequent than Apis-Vespula sensitization [112], and cross-reactivity between allergens of 2 species often poses diagnostic difficulties [113,114]. In cases of difficult interpretation between sensitization Vespula and sensitization to Polistes, the use of Ves v 5 and Pol d 5 seems to be 
helpful in clinical practice, provided that the difference in specific IgE levels between the 2 molecules is particularly significant, with at least double values of one recombinant over the other [114-116]. Furthermore, where available, phospholipases (Pol d 1/Ves v 1) have proved useful in identifying the probable sensitizing species in Vespula/ Polistes-sensitized patients [114]. A new major allergen of the venom of $P$ dominulus, Pol d 3 (dipeptidyl peptidase IV) has recently been identified, although it was found to be crossreactive with both Apis and Vespula venoms [117].

IgE to CCDs can explain multiple positive in vitro results; serum determination of CCDs (bromelain or MUXF3) allows for greater diagnostic accuracy [105]. Polistes venom is CCDfree and is therefore not affected by this cross-reactivity [118].

Figures 1 and 2 show the diagnostic algorithm for cases of double-positive results with Apis-Vespula and VespulaPolistes.

In summary, CRD can be used to discriminate between primary sensitization and cross-reactivity in patients with double-positive results in diagnostic tests with whole extracts, thus enabling the specialist to choose the most suitable venom for VIT and to avoid treatment with double VIT. However, the decision should rely not only on CRD results, but should also take into account the severity of the reaction and the patient's general health status. CRD may also help in the diagnosis of patients with a history of systemic reaction and negative results in standard diagnostic tests $[119,120]$.

CAP-inhibition also makes is possible to distinguish between double sensitization and cross-reactivity, although it may be relatively expensive and its results could prove difficult to interpret [103]. It appears to be very useful in cases

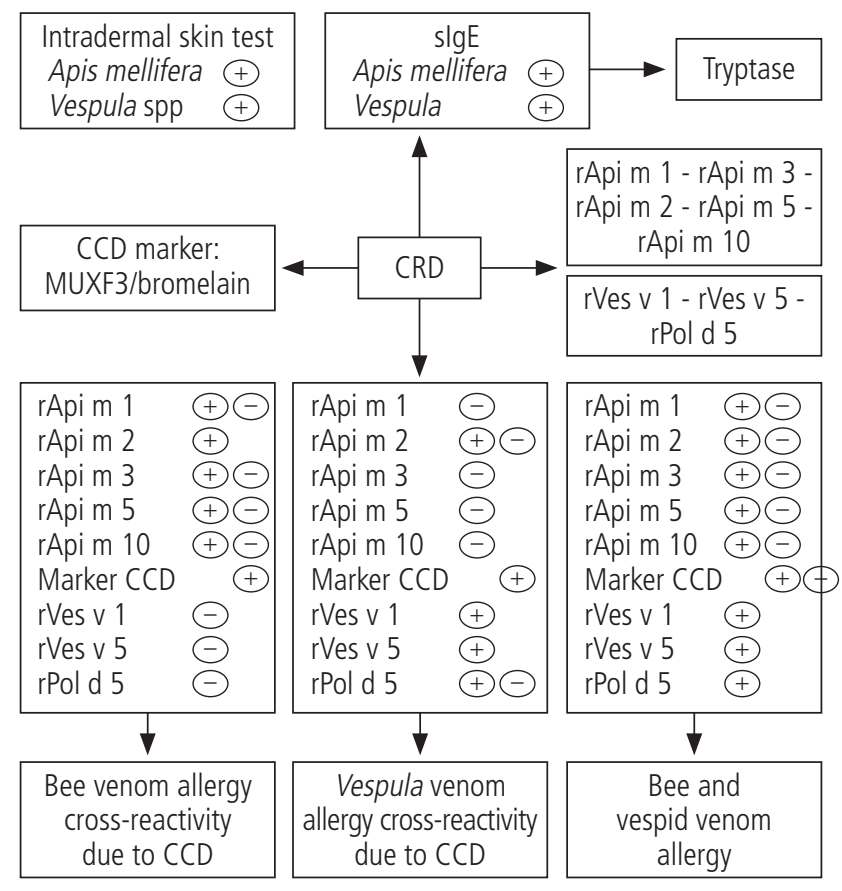

Figure 1. Diagnostic algorithm in honeybee and vespid venom allergy. CRD indicates component-resolved diagnosis; CCD, cross-reactive carbohydrate determinant. of double Vespula-Polistes cosensitization, when CRD cannot discriminate between different possibilities [114,115].

The basophil activation test (BAT) is the most widely used blood cell-based diagnostic test in Europe in selected situations. If performed in highly specialized laboratories, it can identify approximately two-thirds of patients with a positive history and negative skin and serological test results [121]. BAT is also recommended in patients with double-positive results and inconclusive in vivo or in vitro test results with recombinant allergens [119]. Since BAT results are influenced by the presence of venom CCDs, using CCD-free recombinant allergens ensures greater diagnostic accuracy $[119,122]$. The role of BAT as a diagnostic tool in patients with mast cell disorders and negative venom-specific IgE and skin test results remains controversial [123-126].

Sting challenge with a live insect should not be used for diagnostic purposes owing to the risk of potentially severe systemic reactions and its low negative predictive value [127].

In the presence of systemic reactions, basal serum tryptase levels should always be determined, as adults affected by mast cell disorders and/or elevated basal tryptase levels have a significantly greater risk of severe reactions to hymenoptera stings [16,128].

Moreover, patients should be investigated for mastocytosis, even in the absence of cutaneous manifestations compatible with mast cell disorders and increased tryptase levels, and in cases of severe anaphylactic reaction with syncope without urticaria and/or angioedema and a REMA score $\geq 2$ [129]. High basal serum tryptase is not pathognomonic of mastocytosis and can also be found in hematological diseases (especially those of the myeloid lineage), end-stage chronic renal failure,

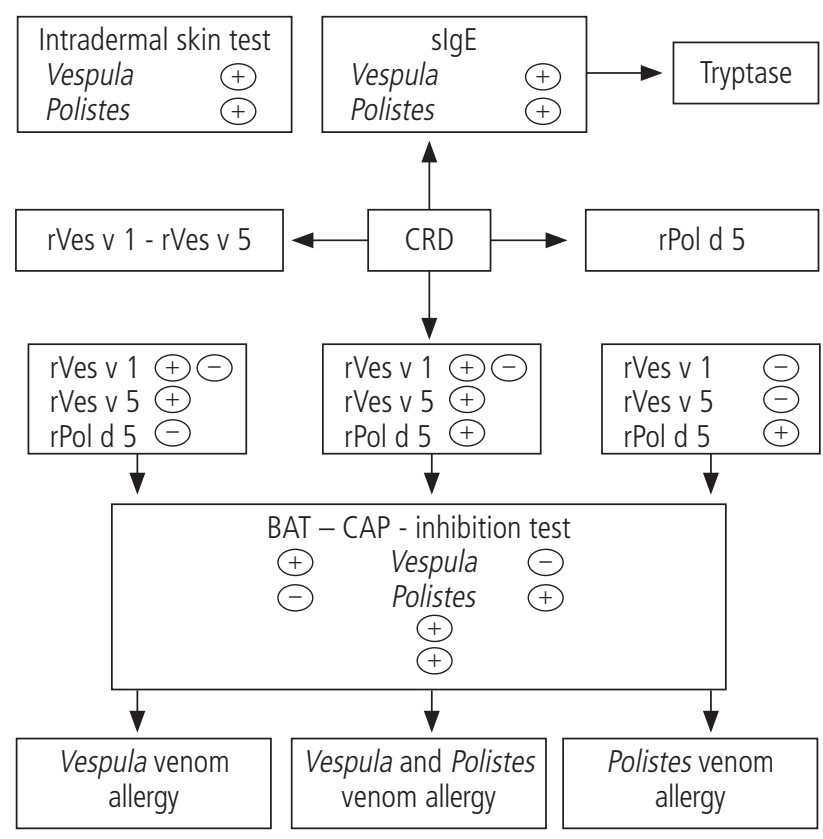

Figure 2. Diagnostic algorithm in Vespula species and Polistes dominula venom allergy. CRD indicates component-resolved diagnosis; BAT, basophil activation test. 
Table 7. Allergological Diagnosis in Hymenoptera Venom Allergy: Practical Considerations

- Skin tests represent the diagnostic gold standard and should be performed at least 2 weeks after the sting; if negative, they should be repeated after 1-2 months.

- Prick tests, even if positive, should be integrated with intradermal tests.

- Simultaneous testing of the same concentration of more venoms is to be preferred. The next concentration should only be tested afterwards.

- Skin tests with venoms are generally safe, even in patients with mastocytosis, if performed by trained personnel in a suitable environment.

- Validated methods are to be used for the determination of serum specific IgE to venom allergens.

- There is no correlation between the severity of a reaction and the scores of in vivo and in vitro diagnostic tests.

- The use of component-resolved diagnosis (CRD) is indicated in cases of polysensitization or negative allergy tests in patients with a proven history of previous systemic reaction.

- At present, CRD makes it possible to distinguish between allergy to Apis mellifera and allergy to Vespula species venoms; the value of CRD is limited in cases of double positivity to Vespula-Polistes.

- The CAP-inhibition method is appropriate in cases of double positivity to Vespula-Polistes, when CRD is not valid.

- The basophil activation test should be carried out in highly specialized laboratories for diagnostic purposes, only in specific situations. Its role as a diagnostic tool in patients with mast cell disorders and negative venom-specific $\operatorname{IgE}$ and skin test results remains controversial.

- When a severe systemic reaction occurs, baseline serum tryptase levels should be measured.

onchocercosis in treatment, and abdominal aortic aneurysm ( 2 cases with anaphylaxis to hymenoptera venom were reported) [130].

Table 7 shows practical considerations in the diagnostic flow chart for hymenoptera venom allergies.

\section{Pediatric Aspects}

Diagnostic tools are no different from those used in adults. Furthermore, in children, the degree of skin sensitization does not correlate with the severity of the reaction [131].

\section{Specific Immunotherapy}

\section{Definition and Mechanisms of Action}

VIT is the therapy of choice for patients who develop a systemic reaction after hymenoptera sting, since it can induce tolerance to venom [33,73,132-134].

VIT consists of an induction phase and a maintenance phase. The induction phase involves subcutaneous administration of increasing doses of the venom extract up to the protective dose, ie, $100 \mu \mathrm{g}$. Protocols used for this purpose differ in length. The maintenance phase involves the administration of fixed amounts of venom at regular time intervals to maintain tolerance.

The mechanisms of action of immunotherapy are numerous and impact at both early and late stages. They include an increase in specific IgG1 and IgG4 levels [135-138], a cytokine shift characterized by reduction in IL-4 and IL-5 and an increase in IFN $\gamma$ [139-141], the reduced expression of adhesion molecules [142], lymphocyte downregulation [143], reduction of mast cell and basophil activation [144,145], immunomodulation by IL-10 [137,146-148], and induction of regulatory T cells $[131,149,150]$.

\section{Indications}

VIT is indicated in the following circumstances: $(a)$ children and adults with a systemic reaction involving organs other than the skin [90]; $(b)$ systemic skin reactions in cases of high risk of exposure and/or impaired quality of life [151] in adults [90]; (c) patients with clonal mast cell disorder and a history of a systemic reaction [152], even though sensitization can be weak or sometimes transitory.

Information on children with cutaneous-mucosal reactions is provided in the appropriate section.

VIT is not generally indicated in cases of LLR, as the risk of progression in systemic reactions is low $(2 \%-7 \%)[89,153,154]$, especially if the LLRs are recurrent $[84,89]$. The clinical efficacy of VIT can be seen in the fact that it reduces the extent of consecutive LLRs $[155,156]$. Its use is not contraindicated in patients with recurrent and severe LLRs. VIT is not indicated unusual reactions (ie, serum sickness-like manifestations, central nervous system manifestations, and hematological, muscle, and renal reactions), where the mechanism of action is unclear [73].

\section{Clinical Efficacy}

Specific subcutaneous immunotherapy for hymenoptera venom is the only treatment able to protect patients from systemic reactions after subsequent stings [90]. Numerous studies have evaluated the efficacy of VIT, both with sting challenge and field sting. In a recent Cochrane Review, the percentage of nonprotection was $2.7 \%$ in treated patients compared with $39.8 \%$ in patients not undergoing immunotherapy [156]. Regarding vespid venom, protection is between $91 \%$ and $96 \%$, while for bee venom it ranges between $77 \%$ and $84 \%$ [14,90,157-167]. Studies performed on European populations, including Italian cases, show that about $70 \%$ of treated patients are allergic to vespids $[164,166]$.

The different methods of preparation of the extracts do not affect their protective capacity; the efficacy of purified aqueous and aluminum hydroxide-adsorbed preparations (the so-called depot preparations) is in fact comparable [168].

As for VIT with Polistes venom, the use of $P$ dominula venom to treat European patients should be preferred, since American Polistes venom extracts have been reported to lack a protective effect $[6,169]$. However, a recent study [170], in which incomplete in vitro cross-reactivity was confirmed, did not detect differences in clinical protection between VIT with a mixture of American Polistes 
and VIT with $P$ dominula after field sting. Further studies are necessary to confirm these data.

Table 8 describes known risk factors for reduced efficacy of VIT.

\section{Protocols}

Over the years, various induction protocols have been proposed with the aim of reducing the incidence of adverse effects while rapidly achieving clinical protection and favoring adherence. According to the chosen protocol, the maintenance dose may be reached in a few weeks, a few days, or a few hours $[33,73,171]$. Conventional and "clustered" protocols do not significantly differ from one another as far as safety is concerned [172]. Ultrarush induction protocols have proved effective [173-175], inducing early changes in immunological parameters associated with the efficacy of VIT (IgE, IgG4) [176]. To increase adherence to VIT, management of immunotherapy protocols can be flexible, for example, by switching from an aqueous extract to a depot extract by the same manufacturer, with no impact on efficacy or safety [177].

The starting dose of VIT is between $0.001 \mu \mathrm{g}$ and $0.1 \mu \mathrm{g}$; however, treatment can be initiated safely from 1-5 $\mu$ g of venom using a rush protocol both in adults and in children [172, 178]. The maintenance dose of $100 \mu \mathrm{g}$ is considered the gold standard in both adults and children and must be increased to $200 \mu \mathrm{g}$ [179] in unprotected patients (usually adults) and, according to some authors, in beekeepers [13]. Once the maintenance dose has been reached, the intervals between doses should be maintained at 4 weeks in the first year and gradually increased to 6-8 weeks in subsequent years, with no reduction in the clinical efficacy of VIT [180]. According to some authors [181-183], after the third year of VIT, the interval can be progressively lengthened up to 12 weeks. Other studies evaluated 6-month intervals; this extension is not currently recommended because it could affect the effectiveness of the treatment [182].

Pharmacovigilance data from the European Medicines Agency indicate that there are no reports of toxic effects of aluminum hydroxide in products for allergen immunotherapy. In VIT with a maintenance dose of $200 \mu \mathrm{g}$ and in VIT with 2 different venoms, it is preferable to use an aqueous extract for at least 1 of the 2 VITs as a precautionary measure [90]. A recent paper analyzed the aluminum concentration in urine and blood in 2 groups of patients: those never treated with aluminum-depot subcutaneous immunotherapy and those treated with aluminum depot VIT. No differences were detected in urine aluminum concentrations between the 2 groups; the same was true of blood using free-gel monovette. However, given the small amount of the free-gel detections, data from blood remain inconclusive [184].

Currently, there are no guidelines in the literature on the management of product deficiency during maintenance, which was reported in 2016 owing to the sudden unavailability of some extracts. A recent multicenter study prospectively collected data on switching VIT and reported that switching VIT from one manufacturer to another is a safe option, if necessary, in patients who had previously tolerated VIT, even without reducing the previous maintenance dose, in a proper medical setting staffed by experienced personnel $[185,186]$. In patients who experienced previous severe systemic reactions during VIT, the treatment should be restarted with a rush/ultrarush protocol in centers experienced in hymenoptera venom allergy and VIT or with a conventional protocol in less experienced centers.

\section{Duration}

In patients with no specific risk factors, VIT should be continued for 5 years [187]. Based on current literature, the

Table 8. Risk Factors for Reduced Effectiveness of Venom Immunotherapy (VIT)

\begin{tabular}{ll}
\hline Risk Factor & Notes \\
\hline Age & $\begin{array}{l}\text { Adults are at higher risk than children, as patients under the age of } 16 \text { generally have a more favorable } \\
\text { prognosis. VIT is not recommended for cutaneous/mucosal systemic reactions in patients under the age } \\
\text { of } 16, \text { except in cases of high risk of exposure or impaired quality of life }[50,152,235,270] .\end{array}$
\end{tabular}

Bee venom

The protection rate for bee venom is lower than for vespid venom $[28,73,160,189,191,271]$.

The reason for this discrepancy is not yet fully understood. Recent studies of molecular allergy have shown that relevant allergens to bee venom may be poorly represented in some extracts used for specific immunotherapy [107,272].

Severity of onset Patients with severe systemic reactions to hymenoptera sting are less likely to have long-term protection (based on the number and frequency of stings received after suspension of immunotherapy) compared with patients who experience milder reactions [159,188,189,241,271,273].

Systemic reactions during VIT

High tryptase values and clonal mast cell diseases

Angiotensin-converting enzyme inhibitors
Patients with adverse reactions to VIT are at greater risk of incomplete protection than patients who tolerate VIT [166,191,271].

In some studies, clonal mast cell diseases are correlated with lower clinical efficacy [207,274]. However, other studies do not support this conclusion and confirm a protection rate of $67 \%-85 \%$

$[100,152,255,256,275]$. In a recent prospective study, protection was $86 \%$ after field sting in patients with clonal mast cell disorders [256]. Overall, VIT should be considered an effective and safe option in these patients.

A single study on 1532 patients reported that this category of drugs could be a risk factor for reduced clinical efficacy, as demonstrated by sting challenge [166]. 
recommended duration of VIT is 3-5 years in adults and children $[73,90,187]$. One year of VIT did not provide sufficient protection in about a quarter of treated patients [188].

After 3 years of VIT, $83 \%$ to $100 \%$ of patients remain protected against subsequent stings for a further 1 to 3 years [158,159,188,189-193].

A VIT schedule equal to or longer than 5 years provides more prolonged efficacy after the interruption [189,194,195]. At present, there are no data on the maintenance of protection for periods longer than 15 years, especially in the case of VIT with bee venom. Table 9 shows the risk factors for relapse after interruption of VIT.

When skin and serological tests yield negative results, VIT can be safely interrupted. However, this rarely occurs [73]. After 5 years of VIT, there is an average reduction in specific IgE of $58 \%-70 \%$ overall compared with baseline and a lower reduction in older patients or in patients with very severe reactions. This reduction is not correlated with lower clinical efficacy [196]. Indeed, the decision to stop VIT cannot be based solely on the reduction in specific serum $\operatorname{IgE}$ levels, since stung and protected patients during VIT have higher IgE levels at the end of the 5-year treatment than patients who have not been stung, although they are clinically protected [196]. It was recently shown that an increase in the $\operatorname{IgG} / \operatorname{IgE}$ ratio correlates with a reduction in the frequency of specific $\mathrm{IgE}$ and skin reactions in patients who have undergone at least 3 years of VIT [197]. However, no validated tests are currently able to predict venom tolerance owing to variability in immunological parameters during VIT [198].

In clinical practice, the patient is rarely stung during VIT, as he/she takes environmental prophylactic measures. It therefore becomes difficult to decide whether or not to suspend VIT in the absence of proof of field protection. Even though the sting challenge test is still the most reliable method and the gold standard for monitoring the effectiveness of VIT [90], it cannot be performed to demonstrate the effectiveness of VIT in some countries for ethical and management reasons [199]. A recently developed microsyringe challenge method [200] has yet to be validated.

Proper management of patients requires a full knowledge of the risk factors that could negatively impact on the protection provided by VIT. According to prevalent expert opinion, patients with mast cell disease should receive lifelong treatment [201,202]. However, this suggestion is not confirmed by controlled studies [90]. A recent study in a selected population indicated that mastocytosis should be considered in patients who experience severe reactions at re-sting after discontinuation of VIT. On this basis, patients with mastocytosis and hymenoptera venom allergy should receive lifelong VIT [203].

The decision to prolong VIT over 5 years should be shared with patients based on specific risk factors and impact on quality of life; there is currently no contraindication to continuing VIT for more than 5 years.

Patients should always be followed up over time; this aspect is not properly addressed in European and American guidelines. Based on current knowledge, the present panel of experts suggests the following:

- Patients not undergoing VIT but equipped with an adrenaline autoinjector because of a previous systemic reaction should attend a follow-up visit in case of resting and have their history updated at each re-order of adrenaline, including refresher training on device use. In the absence of re-sting, it is useful to schedule a followup visit every 2 years, in order to perform skin and/or serological allergy tests before further prescription of adrenaline.

Table 9. Conditions for High Risk of Relapse After Discontinuation of VIT

Risk Factor Notes

Adult population compared with pediatric patients

[73]

Severe pre-VIT systemic reaction

Based on data from 4 prospective studies recruiting 386 patients with severe reactions

Allergy to bee venom at re-sting, $4.1 \%$ had mild and $14.5 \%$ had severe pretreatment reactions [187].

Allergy to bee venom

Systemic reaction caused by VIT

Failure to achieve protection during VIT

Clonal mast cell diseases and elevated baseline tryptase levels

Repeated stings

Persistence of high scores in diagnostic tests after 5 years of VIT
The risk of systemic reactions after discontinuation of VIT for bee was $16 \%$ vs $8 \%$ of patients treated with wasp venom [189].The reasons, which are not entirely known, are partly related to the amount of venom delivered with sting and to the amount of venom administered in VIT. It has also been hypothesized that some major bee allergens may be missed or underrepresented in extracts used for VIT [109].

Patients who developed systemic reactions to VIT had a $38 \%$ risk of re-sensitization compared with those who tolerated treatment (7\%) [276].

Please refer to the mastocytosis section.

According to European studies, patients repeatedly stung after discontinuation of VIT have a greater risk of systemic reactions that may become progressively more severe [189]. Professionals who are particularly at risk include beekeepers and gardeners, who need treatment for an indefinite period.

Abbreviation: VIT, venom immunotherapy. 
- Patients undergoing VIT should undergo monitoring of skin reaction and/or determination of specific $\operatorname{IgE}$ at 3 and 5 years or in the case of a systemic reaction to a field sting.

- Patients at risk of multiple stings or with risk factors for relapse after interruption of VIT should attend a follow-up visit in case of re-sting and have their clinical history updated at each re-order of adrenaline, including refresher training on device use.

\section{Adverse Reactions}

The literature reveals considerable variation in the incidence of adverse effects due to VIT (0\%-46\%) [204,205]. This is likely due to multiple factors, including different classification systems for severity, differences in the quality of extracts (nonpurified, aqueous, and depot extracts), and differences in administration protocols.

A recent systematic review of the literature [90] examined 11 observational studies: VIT was associated with a $14.2 \%$ risk of adverse events in patients treated with bee venom and a $2.8 \%$ risk in those treated with vespid venom. Another systematic review [206] reported a mean frequency of $28.9 \%$ for adverse events with bee venom, of which $50.4 \%$ were systemic reactions and $10 \%$ local extended reactions.

Large-scale studies showed that most reactions to VIT occurred in the build-up phase, including systemic reactions (up to $20 \%$ [1.9\% during the build-up phase, $0.5 \%$ during maintenance from a total of 26601 injections]), of which $8.4 \%$ were moderate to severe [204].

LLRs to VIT are frequent, especially in the build-up phase; they do not represent a risk factor for subsequent systemic reactions, do not require dose reduction, and do not prevent the protective dose from being reached. In the case of systemic reactions, it is preferable to reduce the dosage in the build-up phase (eg, by stepping down 1 or 2 doses) and continue with the last well-tolerated dose [90].

The risk factors for systemic reactions during VIT are bee venom, high basal tryptase values in patients allergic to wasps, mast cell clonal diseases, and rush and ultrarush protocols [73,204,207,208].

However, some authors do not consider rush or ultrarush induction protocols to be dangerous, since they were able to demonstrate a low risk of systemic reactions and a safety profile equivalent to or even better than slower protocols [163,209-211].

Local adverse reactions are less frequent with depot extracts than with aqueous extracts [212,213]. A systematic review confirmed that the incidence of systemic reactions is significantly higher for bee venom than for vespid venom (25.1\% vs 5.8\%), while no differences were found between aqueous and depot extracts in treated patients [214]. However, this review did not compare nonpurified aqueous extracts with purified aqueous extracts. In fact, the use of purified aqueous extracts seems to correlate not only with a lower frequency of major local reactions, but also with a lower frequency of systemic reactions than nonpurified extracts [215,216].

Results from double-blind, placebo-controlled studies show that premedication with antihistamines improves tolerance to VIT while maintaining efficacy [217-220]. On this basis, recent EAACI guidelines [90] recommend antihistamines, which can prevent extensive local reactions and mild systemic reactions. The possibility of masking warning signs and symptoms of more severe reactions, especially if rapid protocols are used, led the Italian expert panel to indicate this treatment as optional.

Off-label premedication with omalizumab can be successfully implemented in patients who experience systemic reactions to VIT and when premedication with antihistamines is insufficient $[221,222]$.

\section{VIT and Pregnancy}

Studies on the safety of VIT in pregnancy are limited [223,224], mainly for ethical reasons. One of the potential risks of immunotherapy, in addition to the management of possible adverse reactions, could be the induction of a $\mathrm{T}_{\mathrm{H}} 2-\mathrm{T}_{\mathrm{H}} 1$ cytokine shift that acts against the overall $\mathrm{T}_{\mathrm{H}} 2$ profile of pregnancy and has been claimed to prevent fetal rejection [225]. In a 1990 study of 26 patients with multiple pregnancies undergoing VIT, the authors estimated a $3 \%-5 \%$ risk of field sting anaphylaxis in women not undergoing VIT during pregnancy, while the risk of anaphylactic reaction during VIT was $1 \%$ in the maintenance phase and $5 \%$ in the build-up phase. In addition, anaphylaxis has potentially severe consequences for the fetus. The risk of maternal-fetal complications in pregnant women undergoing VIT was similar to that of women not undergoing VIT [224].

In a 2002, Markert et al [226] reported a case of preterm delivery due to placental abruption at week 24 in a woman who had started the build-up phase of immunotherapy during the first weeks of gestation. VIT was continued at the maintenance dose of $50 \mu \mathrm{g}$. Analysis of the placenta demonstrated a $\mathrm{T}_{\mathrm{H}} 1$ pattern with infiltrated cytotoxic $\mathrm{T}$ lymphocytes [226]. In contrast, a more recent case report of in vitro fertilization considered VIT to be safe [227].

In conclusion, as confirmed by recent European guidelines [228], immunotherapy should not be started during pregnancy. However, given the low risk of adverse effects, VIT should not be interrupted during pregnancy if the patient is already taking and tolerating VIT [204].

\section{Adherence to VIT}

Adherence to specific immunotherapy is key to successful management of patients with respiratory allergies [229]. In the case of VIT, a recent Italian study showed high percentages of adherence at 3 years (95\%) and 5 years (84\%) of treatment [230].

\section{Pediatric Aspects}

Although the efficacy of VIT is known in children, there are no double blind, placebo-controlled trials in pediatric patients [231]. Treatment is recommended in children who experience systemic reactions with cardiovascular and/or respiratory involvement after hymenoptera stings [73,231].

In children who only experience cutaneous systemic reactions, VIT is not routinely performed [90,232,233], since a long-term prospective study has shown that children with this type of reaction have a $10 \%$ risk of systemic reaction [131]. However, there may be particular situations of increased risk of re-sting (eg, children of beekeepers), possibly associated with 
concern on the part of parents and children, distance from an emergency department, and unavailability of school staff who know how to administer antiallergic drugs. These conditions also highlight the need for VIT in cases of children affected only by urticaria [73].

As far as the risk of systemic reactions with respiratory or cardiovascular involvement is concerned, an observational study of pediatric patients followed for 15-20 years showed that the risk of recurrence of anaphylaxis in untreated children was $32 \%$, compared with $1 \%-3 \%$ in those treated with VIT [154]. In a recent 6-year follow-up European pediatric study, $62 \%$ of children allergic to venom and not treated with
VIT tolerated subsequent stings, whereas $18 \%$ had severe systemic reactions [234]. The proportion of therapeutic failure of VIT is lower in children than in adults (about $2 \%$ of treatments) $[49,189,235]$.

Induction patterns in children are similar to those used in adults [131]. Regarding accelerated protocols, a pediatric study [236] of 43 children and adolescents (aged 4 to 18 years, with a 1-4 Mueller grade systemic reaction after bee or wasp sting) undergoing ultrarush VIT found no systemic reactions. A recent study of pediatric and adult patients confirmed the tolerability of the rush schedule in children [237]. Another study compared the safety of 3-day rush induction protocols

Table 10. Pediatric Aspects of Hymenoptera Venom Allergy

Epidemiology Hymenoptera venom allergy is the second cause of severe reactions in children (20.2\%), after food allergy [19] Prevalence: asymptomatic sensitization, 3.7\% [42]; large local reactions, between $0.9 \%$ [43] and 20.8\% [44]; systemic reactions, $<1 \%[15,42]$.

Risk factors for systemic reactions [45,46]: bronchial asthma, atopy (according to some studies) Clinical: the cutaneous and cardiocirculatory systems are the most affected; skin symptoms are the only clinical manifestation in $60 \%$ of cases [47].

Prognosis: favorable regarding re-sting in studies with sting challenge [48] and field sting [49,50].

Diagnosis

Specific immunotherapy

(VIT)

Quality of Life

Use of adrenaline
- Diagnosis is no different from that of adults

- The degree of skin sensitization does not correlate with the severity of the reaction [131].

Indications:

- Children who develop a systemic reaction with cardiovascular and/or respiratory involvement [73,232].

- VIT is usually not administered in children with only cutaneous systemic reactions $[90,233]$ owing to the very low risk of developing a more severe systemic reaction.

- Children with an increased risk of exposure (eg, children of beekeepers) and/or children or their parents who show anxiety, are living far from emergency departments, or attending school not staffed with personnel trained to administer antiallergic drugs may also undergo VIT in cases of skin reactions only [73].

Risk of anaphylaxis at re-sting:

- Children not undergoing VIT: $32 \%$ vs $1 \%-3 \%$ of patients treated with VIT [154].

- Recent European study with 6-year follow-up: $18 \%$ of non-VIT-treated patients (while $62 \%$ tolerated subsequent stings) [233].

Efficacy:

- The percentage of failure of VIT in children is lower than that of adults (about 2\%) [49,189,235].

- The prognosis after discontinuation of VIT is better than that of adults: only $5 \%$ of children with a severe pretreatment reaction develop nonsevere systemic reactions at re-sting [149], compared with 16\% of adults [241].

Induction schemes:

- As in adults [131].

- Accelerated (rush, ultrarush) and clustered protocols are well tolerated by children [236-240]

- As in adults, avoid excessively rapid patterns with bee venom

- As in adults, the maintenance dose is $100 \mu \mathrm{g}$, to be increased to $200 \mu \mathrm{g}$ in unprotected patients

Duration:

- The panel of experts suggests at least 5 years of VIT in pediatric patients

- Proper follow-up and appropriate educational programs are necessary.

- Allergy to hymenoptera venom in children can have a negative impact on the quality of life of their parents.

- There are specific questionnaires on the quality of life of pediatric patients allergic to hymenoptera venom and their parents [269].

Dose: intramuscular adrenaline in the vastus lateralis muscle at $0.01 \mathrm{mg} / \mathrm{kg}$ (maximum dosage $0.3 \mathrm{mg}$ )

Autoinjector:

- The fixed dosage involves a risk of administering a higher or lower dose of adrenaline; for children weighing between 15 and $30 \mathrm{~kg}$ with severe anaphylactic reaction or concomitant bronchial asthma, it is advisable to use the adult dosage.

- It should be prescribed to children with systemic reactions (not just cutaneous reactions), with a high risk of exposure, risk factors for lacking clinical protection, elevated baseline mast cell tryptase levels, or mast cell disorders $[28,33,70,71]$. 
with conventional 4-month regimens [238]: no differences were found between the protocols in terms of systemic reactions (19\% and $23.2 \%$ with rush and conventional protocols, respectively). In a 2016 study [239], the ultrarush induction protocol of Birnbaum et al [240] (101 $\mu \mathrm{g}$ cumulative in 210 minutes) was compared in adults and children (systemic reactions in $7.7 \%$ of adults vs $3.7 \%$ of children). It is important to remember that, as in adults, excessively rapid schedules should be avoided when using bee venom [237].

Children have a better prognosis than adults with regard to the maintenance of efficacy upon discontinuation. Golden et al [154] followed patients for 20 years and found that nonsystemic reaction recurred at re-sting in only $5 \%$ of children with a severe pretreatment reaction, compared with $16 \%$ of adults [241].

Among 40 children who received VIT for a mean of 3 years, $50 \%$ developed a new anaphylactic reaction after a median follow-up of 13 years; of note, $95 \%$ had not received adequate follow-up after discontinuation of VIT [242].

In view of these data, the panel of experts suggests that VIT should last for at least 5 years in pediatric patients. Moreover, children should also undergo periodic check-ups, and suitable educational programs are necessary.

Table 10 summarizes the pediatric aspects of hymenoptera venom allergy.

\section{Management of the Patient With Concomitant Diseases}

\section{Heart Disease}

The presence of cardiovascular disease is a major risk factor in hymenoptera venom-allergic patients owing to the severity of anaphylaxis after a sting. In fact, increased mast cell density has been identified in arterial intima and adventitia in ischemic heart disease, aortic valve stenosis, and hypertrophic cardiomyopathy [243]. Furthermore, mast cells in ischemic myocardium are richer in histamine and tryptase than mast cells in healthy myocardium.

Venom components can induce the release of serotonin and adrenaline, which increase platelet aggregation, thus increasing the likelihood of thrombosis resulting from an increase in factor $\mathrm{V}$ and the release of a thromboplastin-like substance from the vessel wall. These and other substances released by mast cells could have a negative inotropic and chronotropic effect. During the anaphylactic reaction, de novo synthesis of LTC4 and PGD2 at the level of the heart may result in vasoconstriction. Similarly, in some patients with coronary artery disease, stimulation of $\mathrm{H}_{1}$ receptors may cause vasoconstriction of large-caliber coronary arteries, in contrast to patients with a healthy myocardium [244]. Activation of metalloproteinase also degrades the connective tissue of atheromatous plaques, thus increasing the risk of ischemia.

Physiologically, the decrease in blood pressure that occurs in the anaphylactic reaction leads to reduced perfusion in the sinuses of Valsalva and to coronary hypoperfusion.

Kounis syndrome [245], also known as cardiac anaphylaxis, is characterized by signs and symptoms that are similar to those of coronary syndrome. This condition may be due to the direct action of the venom on the coronary endothelium or to degranulation of mast cells due to the allergic reaction, with direct release of inflammatory mediators into the coronary vascular system (histamine, kinase, tryptase) and synthesis of leukotrienes, which act as powerful vasoconstrictors of the coronary arteries [246].

In patients allergic to hymenoptera venom, in whom a subsequent allergic reaction may be more severe or even fatal, VIT is elective, even if the patient has had a myocardial infarction or severe ventricular arrhythmia. In these patients, VIT was found to be associated with a low incidence of systemic reactions and with a certain degree of efficacy [247].

The patient with heart disease is often treated with ß-blockers and angiotensin-converting enzyme (ACE) inhibitors, which are commonly prescribed for hypertension and heart failure. B-Blockers can reduce the efficacy of adrenaline administered to treat systemic reactions to hymenoptera venom. However, their use is not contraindicated during VIT [228]. Indeed, a recent report indicated that $\beta$-blockers had no significant clinical effects with respect to the need for adrenaline dosing in patients with anaphylaxis seen in the emergency department [248].

Suspension of $\beta$-blockers, which is limited to the rush or ultrarush induction phase of VIT, should be discussed with cardiologists. ACE inhibitors can increase the severity of the reaction in patients not treated with VIT, although they do not seem to increase the risk of systemic reactions during VIT. According to a recent study [166], ACE inhibitors constitute a risk for reduced protection of VIT to insect challenge. Therefore, their suspension remains at the discretion of the clinician based on the risk-benefit ratio [16].

Before starting VIT, cardiovascular disease, its pharmacological treatment, and the risk of anaphylaxis with consequent administration of adrenaline should be carefully evaluated on an individual basis, preferably together with the consulting cardiologist (strength of recommendation, D).

\section{Elderly Patients}

According to the guidelines of EAACI and the American Academy of Allergy, Asthma and Immunology (AAAAI), VIT should be taken into consideration in older adults, even if they have experienced a nonsevere systemic reaction, provided that they have risk factors such as concomitant vascular diseases, treatment with ACE inhibitors and/or ß-blockers, severe chronic obstructive pulmonary disease, and reduced quality of life due to the previous anaphylactic event $[73,87]$.

No increased risk of adverse effects or an increase in emergency treatments of elderly patients has been demonstrated to date (strength of recommendation, D).

\section{Malignancy}

Malignant neoplasms are considered absolute contraindications for specific immunotherapy with aeroallergens, although not all guidelines agree. This contraindication has been established for safety and ethical reasons [249], since the risk of an exacerbation of neoplastic disease by allergen immunotherapy is only theoretical, although a possible immunological interaction between neoplasm, cancer treatments, and allergen 
immunotherapy cannot be completely excluded. However, in patients allergic to hymenoptera venom with a high risk of severe reactions to subsequent stings (eg, previous life-threatening reaction or clonal mast cell diseases), VIT appears to prevent fatal events even in the presence of cancer [228,250] (strength of recommendation, D).

\section{Autoimmune Diseases and Immunodeficiency}

Some guidelines consider multiorgan autoimmune diseases in remission to be relative contraindications for immunotherapy. If autoimmune diseases are clinically active, the contraindication is absolute [228] (strength of recommendation, D).

VIT is not contraindicated in patients with organ-specific autoimmune diseases (eg, diabetes mellitus, Hashimoto thyroiditis, Crohn disease, ulcerative colitis, rheumatoid arthritis), provided the disease is stabilized before starting treatment [251] (strength of recommendation, D).

Immunodeficiency has a different impact and a different pathophysiological mechanism. According to some guidelines, concomitant treatment with immunosuppressive drugs means that allergen immunotherapy is contraindicated, since they could have a negative impact on the effectiveness of VIT. HIV infection, in particular, is a relative contraindication to VIT that can be assessed on an individual basis (strength of recommendation, D). AIDS with a confirmed category C disease (1993 Revised Classification, Centers for Disease Control) is an absolute contraindication to VIT [228] (strength of recommendation, NR).

\section{Mastocytosis}

Anaphylaxis is the most severe clinical manifestation of systemic mastocytosis, and hymenoptera stings are reported to be the most frequent cause (19\%-53\% of cases) [252].

The preferential association between mastocytosis and allergy to hymenoptera venom is well known and widely studied [100]. The prevalence of hymenoptera venom allergy in the European adult population is between $0.3 \%$ and $8.9 \%$ and rises to $20 \%-30 \%$ in patients with mast cell disorders $[3,252,152]$. On the other hand, the prevalence of systemic mastocytosis in the general population is $1-1.3$ cases per 10000 , which increases significantly in patients with hymenoptera venom allergy $(5 \%-8 \%)[25,252]$.

Patients with systemic mastocytosis without skin involvement presenting hymenoptera venom anaphylaxis probably represent a specific phenotype characterized by an excellent prognosis, male predominance, lower values of serum tryptase, and lower proportions of bone marrow mast cells than in indolent forms. Moreover, this phenotype does not include other symptoms due to mediator release and affects no myeloid lineages other than mast cells [253]. In contrast, hymenoptera anaphylaxis appears to be absent in patients with aggressive forms of systemic mastocytosis, despite the greater mast cell burden [254]. In patients with onset of mastocytosis after hymenoptera anaphylaxis, progression to aggressive forms and associated hematological malignancies are rarely reported.

After initial debate focusing mainly on the safety and efficacy profile of VIT in patients with mastocytosis [100], this treatment is now considered safe and efficacious $[252,255,256]$, inducing protection from severe allergic reactions to subsequent stings.

Given reports of life-threatening and even fatal reactions to hymenoptera stings after discontinuation of treatment, long-term VIT (probably lifelong) may be recommended $[100,203]$. Patients not adequately protected by the usual maintenance dose of $100 \mu \mathrm{g}$ should have their dose increased to $200 \mu \mathrm{g}$ [252]. Patients affected by systemic mastocytosis with a history of anaphylaxis should always carry 2 adrenaline autoinjectors. This recommendation is also valid for patients receiving VIT [252].

\section{Professional Aspects}

Hymenoptera stings are the most frequent cause of occupational anaphylaxis and can be attributed to a specific work environment [257].

Since exposure to repeated stings is a key factor for the development of allergic reactions, persons working outdoors or in environments where hymenoptera live are considered to be at high risk. In addition to beekeepers [13], for whom a specific risk is recognized, other workers such as foresters, farmers, gardeners, truck drivers, masons, and electricians [258,259] also experience systemic reactions more frequently, as do greenhouse workers, who are exposed to bumblebee stings $[8,260]$. For these categories, hymenoptera venom allergy can be considered an occupational disease $[259,261]$ necessitating specific primary prevention measures [262]. Hymenoptera venom allergy is a recognized cause of work disability that can require a worker to change or leave his/her profession in order to reduce the risk of exposure [263].

Given its degree of effectiveness, VIT is also recommended for moderate systemic reactions to enable the worker at risk to continue working [14,190,257,262].

Some European authors recommend verifying the efficacy of treatment through sting challenge before the resumption of work [262], although this clinical practice is not currently permitted in Italy. A maintenance dose of $200 \mu \mathrm{g}$ may be indicated for beekeepers [73]. Persons with occupational bumblebee-induced anaphylaxis have a low degree of crossreactivity with bee venom and therefore should undergo VIT with bumblebee venom [8]. Since workers who are frequently exposed to stings have a higher risk of relapse after discontinuation of VIT, some experts recommend continuing treatment for as long as the patient is at risk owing to his/her profession [262].

A recent Italian study conducted on 184 patients with anaphylactic reactions to hymenoptera venom showed an occupational cause in $17.4 \%$ of cases; of these, $71.8 \%$ continued to work after having received VIT. Re-stung workers $(31.2 \%)$ were effectively protected [261]. The impact of VIT on professional activity increases with occupational risk [263].

\section{Quality of Life}

A history of previous allergic reactions to hymenoptera has a negative influence on the quality of life of affected patients. Many live their lives in constant anxiety about being stung and 
experiencing the same or even more severe and potentially fatal reactions [264].

Questionnaires were validated to specifically evaluate the quality of life of persons allergic to vespids $[151,265]$, including $P$ dominula, in the Mediterranean area [266]. Randomized controlled clinical trials evaluating the impact of hymenoptera venom allergy on quality of life confirmed that immunotherapy is associated with a significant improvement in quality of life 1 year after initiation of therapy [151,267].

People undergoing immunotherapy have a better quality of life than those who are only prescribed the adrenaline autoinjector, even if they experienced a systemic reaction of medium severity such as urticaria or angioedema. Moreover, sting challenge results in a significant improvement in diseasespecific quality of life in patients allergic to hymenoptera venom receiving VIT [265-268].

These findings should be taken into account when choosing whether to start immunotherapy in persons who experienced a cutaneous systemic reaction, and in some cases, immunotherapy should be preferred to the prescription of adrenaline autoinjectors alone [81].

In the case of children allergic to hymenoptera venom, the disease can have an impact on the quality of life of their parents. Through specific questionnaires, it was shown that parents of hymenoptera venom-allergic children have a worse quality of life: in addition to feeling responsible for the life and health of their children, parents fear the severe consequences of a sting [269].

\section{Conclusions}

The severity of allergic reactions to hymenoptera stings varies considerably and can sometimes be fatal. Although the epidemiological burden of hymenoptera venom allergy is similar to that of food allergy, awareness of this problem is poor in the general population and among health care providers and political decision-makers. Similarly, the availability of acute emergency treatment (adrenaline autoinjector) and long-term immunotherapy modifying the natural history of this allergy remains poor. This observation is somewhat paradoxical considering the numerous scientific innovations in this field over the past $5-10$ years.

It is therefore mandatory to improve both knowledge and management of this condition and to ensure that clinicians are aware that VIT is by far the most effective form of allergenspecific immunotherapy available.

This consensus document should be made accessible to health care professionals and to anyone looking for information on allergic reactions to hymenoptera venom. It provides practical advice supported by scientific evidence on both diagnosis and therapy and can be used by specialists in daily clinical practice.

As in many other areas of medicine, studies performed in the coming years $[90,151]$ will provide data that will facilitate the treatment of allergic patients.

\section{Funding}

The authors declare that no funding was received for the present study.

\section{Conflicts of Interest}

The authors declare that they have no conflicts of interests.

\section{References}

1. Moro Moro M, Tejedor Alonso MA, Esteban Hernández J, Múgica García MV, Rosado Ingelmo A, Vila Albelda C. Incidence of anaphylaxis and subtypes of anaphylaxis in a general hospital emergency department. J Investig Allergol Clin Immunol. 2011;21:142-9.

2. Oxford Centre for Evidence-based Medicine. Levels of Evidence and Grades of Recommendation. http://www.cebm. net/in-dex.aspx?o=1025 (Accessed 25th March 2013) 2013.

3. Bilò BM, Ruëff $F$, Mosbech $H$, Bonifazi $F$, Oude Elberink JNG, the EAACI Interest Group on Insect Venom Hypersensitivity. Diagnosis of hymenoptera venom allergy. Allergy. 2005:60:1339-49.

4. Seebach J-D, Bucher C, Anliker M, Schmid-Grendelmeier $P$, Wüthrich B. Ant venom a rare case of allergic reactions in Switzerland. Schweiz Med Wochenschr. 2000;130:1805-13.

5. Fernández-Meléndez S, Miranda A, Garcia González JJ, Barber D, Lombardero M. Anaphylaxis caused by imported red fire ant stings in Málaga, Spain. J Investig Allergol Clin Immunol. 2007;17:48-9.

6. Severino MG, Campi P, Macchia D, Manfredi M, Turillazzi S, Spadolini I, et al. European Polistes venom allergy. Allergy. 2006;61:860-3.

7. Chugo S, Lizaso MT, Alvarez MJ, Arroabaren E, Lizarza S, Tabar Al. Vespa velutina nigritorax: A New Causative Agent in Anaphylaxis. J Investig Allergol Clin Immunol. 2015;25:231-2.

8. de Groot H. Allergy to bumblebees. Curr Opin Allergy Clin Immunol. 2006;6:294-7.

9. Cruz $S$, Vega A, Fernández $S$, Marquès L, Baltasar M, Alonso $A$, et al. Report from the Hymenoptera Committee of the Spanish Society of Allergology and Clinical Immunology: immunotherapy with bumblebee venom. J Investig Allergol Clin Immunol. 2012;22:377-8.

10. Biló MB, Bonifazi F. The natural history and epidemiology of insect venom allergy: clinical implications. Clin Exp Allergy. 2009:39:1467-76.

11. Mukai K, Tsai M, Starkl P, Marichal T, Galli SJ. IgE and mast cells in host defence against parasites and venoms. Sem Immunopathol. 2016;38:581-603.

12. Sturm GJ, Schuster C, Kranzelbinder B, Wiednig M, GroseljStrele A, Aberer W. Asymptomatic sensitization to hymenoptera venom is related to total immunoglobulin E levels. Int Arch Allergy Immunol. 2009:148:261-4.

13. Müller UR. Bee venom allergy in beekeepers and their family members. Curr Opin Allergy Clin Immunol. 2005;5:343-7.

14. Bilò MB, Antonicelli L, Bonifazi F. Honeybee venom immunotherapy: certainties and pitfalls. Immunotherapy. 2012;4:1153-66.

15. Biló MB, Bonifazi F. Epidemiology of insect venom anaphylaxis. Curr Opin Allergy Clin Immunol. 2008;8:330-7.

16. Ruëff F, Przybilla B, Biló MB, Müller U, Scheipl F, Aberer W, Birnbaum J, et al. Predictors of severe systemic anaphylactic reactions in patients with Hymenoptera venom allergy: importance of baseline serum tryptase - a study of the 
European Academy of Allergology and Clinical Immunology Interest Group on Insect Venom Hypersensitivity. J Allergy Clin Immunol. 2009;124:1047-54.

17. Marqués L, Vega A, Muñoz E, Moreno-Ancillo A. Epidemiologic observations on Hymenoptera allergy in Spain: the Alergológica 2005 study. J Investig Allergol Clin Immunol. 2009;19:51-5.

18. Biló MB. Anaphylaxis caused by Hymenoptera stings: from epidemiology to treatment. Allergy. 2011;66:35-7.

19. Worm M, Moneret-Vautrin A, Scherer K, Lang R, FernandezRivas $M$, Cardona V, et al. First European data from the network of severe allergic reaction (NORA). Allergy. 2014;69:13971404.

20. Minale P, Bignardi D, Troise C, Voltolini S, Dignetti P. A regional approach to unmet needs in anaphylaxis. Eur Ann Allergy Clin Immunol. 2016;3:88-93.

21. Savi E, Peveri S, Magnacavallo A, Bisagni M. Operative procedure for the monitoring of anaphylactic reactions and the prevention of recurrence. Eur Ann Allergy Clin Immunol. 2012;44:117-21.

22. Pumphrey RS. Fatal anaphylaxis in UK. 1992-2001. In: Bock G, Goode J, eds. Anaphylaxis. Novartis Found Symp 257. Chichester, UK: John Wiley and Sons, 2004;116-28.

23. Golden DB. Insect sting allergy and venom immunotherapy: a model and a mystery. J Allergy Clin Immunol. 2005;115:43947.

24. Pucci S, Antonicelli L, Biló MB, Garritani MS; Bonifazi F. Shortness of interval between two stings as risk factor for developing Hymenoptera venom allergy. Allergy. 1994;49:8946.

25. Bonadonna P, Perbellini O, Passalacqua G, Caruso B, Colarossi S, Dal Fior D, et al. Clonal mast cell disorders in patients with systemic reactions to Hymenoptera stings and increased serum tryptase levels. J Allergy Clin Immunol. 2009;123:680-6.

26. Pravettoni V, Piantanida M, Primavesi L, Forti S, Pastorello EA. Basal platelet-activating factor acetylhydrolase: prognostic marker of severe Hymenoptera venom anaphylaxis. J Allergy Clin Immunol. 2014;133:1218-20.

27. Simons FE, Ardusso LR, Bilò MB, El-Gamal YM, Ledford DK, Ring J, et al. World Allergy Organization anaphylaxis guidelines: summary. J Allergy Clin Immunol. 2011;127:58793.

28. Muraro A, Roberts G, Worm M, Bilò MB, Brockow K, Fernández Rivas $M$, et al. Anaphylaxis: guidelines from the European Academy of Allergy and Clinical Immunology. Allergy. 2014;69:1026-45.

29. Sampson HA, Muñoz-Furlong $A$, Campbell $R L$, Adkinson NF Jr, Bock SA, Branum A, et al. Second symposium on the definition and management of anaphylaxis: summary report-Second National Institute of Allergy and Infectious Disease/ Food Allergy and Anaphylaxis Network symposium. J Allergy Clin Immunol. 2006;117:391-7.

30. Mueller H. Diagnosis and treatment of insect sensitivity. J Asthma Res. 1966:3:331-3.

31. Ring J, Messmer K. Incidence and severity of anaphylactoid reaction to colloid volume substitutes. Lancet. 1977:466-469.

32. Brown SG. Clinical features and severity grading of anaphylaxis. J Allergy Clin Immunol. 2004;114:371-6.

33. Krishna MT, Ewan PW, Diwakar L, Durham SR, Frew AJ, Leech SC, et al. Diagnosis and management of hymenoptera venom allergy: British Society for Allergy and Clinical Immunology (BSACI) guidelines. Clin Exp Allergy. 2011;41:1201-20.

34. Muraro A, Fernandez-Rivas M, Beyer K, Cardona V, Clark A, Eller $E$, Hourihane JO, et al. The urgent need for a harmonized severity scoring system for acute allergic reactions. Allergy. 2018. doi: 10.1111/all.13408.

35. Kounis NG. Kounis syndrome: an update on epidemiology, pathogenesis, diagnosis and therapeutic management. Clin Chem Lab Med. 2016;54:1545-59.

36. Ridolo E, Olivieri E, Montagni M, Rolli A, Senna GE. Type I variant of Kounis syndrome secondary to wasp sting. Ann Allergy Asthma Immunol. 2012;109:79-81.

37. Lee JM, Greenes DS. Biphasic anaphylactic reactions in pediatrics. Pediatrics. 2000;106:762-6.

38. Lee S, Sadosty AT, Campbell RL. Update on biphasic anaphylaxis. Curr Opin Allergy Clin Immunol. 2016;16:346-51.

39. Xie C, Xu S, Ding F, Xie M, Lv J, Yao J, et al. Clinical features of severe wasp sting patients with dominantly toxic reaction: analysis of 1091 cases. PLoS ONE. 2013;8:e83164.

40. Mingomataj EÇ, Bakiri AH, Ibranji A, Sturm GJ. Unusual reactions to hymenoptera stings: what should we keep in mind? Clin Rev Allergy Immunol. 2014;47:91-9.

41. Mingomataj EC, Bakiri AH. Episodic haemorrhage during honeybee venom anaphylaxis: potential mechanisms. J Investig Allergol Clin Immunol. 2012;22:237-44.

42. Novembre $E$, Cianferoni $A$, Bernardini R, Veltroni M, Ingargiola $A$, Lombardi $E$, Vierucci $A$. Epidemiology of insect venom sensitivity in children and its correlation to clinical and atopic features. Clin Exp Allergy. 1998;28:834-8.

43. Quercia O, Incorvaia C, Marseglia GL, Puccinelli P, Dell'Albani I, Emiliani $F$, et al. Prevalence and incidence of reactions to insect stings in children: a reappraisal. Minerva Pediatr. 2014;66:257-60.

44. Graif Y, Romano-Zelekha O, Livne I, Green MS, Shohat T. Allergic reaction to insect sting: results from a national survey of 10000 junior high school children in Israel. J Allergy Clin Immunol. 2006;117:1435-9.

45. Graif Y, Romano-Zelekha O, Livne I, Green MS, Shohat T. Increased rate and greater severity of allergic reactions to insect sting among schoolchildren with atopic diseases. Pediatr Allergy Immunol. 2009;20:757-62.

46. Yavuz ST, Sahiner UM, Buyuktiryaki B, Soyer OU, Sackesen C, Sekerel BE, Tuncer A. Clinical Features of Children with Venom Allergy and Risk Factors for Severe Systemic Reactions. Int Arch Allergy Immunol. 2013;160:313-21.

47. Schuberth KC, Lichtenstein LM, Kagey-Sobotka A, Szklo M, Kwiterovich KA, Valentine MD. An epidemiologic study of insect allergy in children. I. Characteristics of the disease. J Pediatr. 1982;100:546-51.

48. Schuetze GE, Forster J, Hauk PJ, Friedl K, Kuehr J. Bee-venom allergy in children: Long-term predictive value of standardized challenge tests. Pediatr Allergy Immunol. 2002;13:18-23.

49. Valentine MD, Schuberth KC, Kagey-Sobotka A, Graft DF, Kwiterovich KA, Szklo M, Lichtenstein LM. The value of immunotherapy with venom in children with allergy to insect stings. N Engl J Med. 1990;323:1601-3.

50. Reisman RE. Natural history of insect sting allergy: relationship of severity of symptoms of initial sting anaphylaxis to re-sting reactions. J Allergy Clin Immunol. 1992;90:335-9. 
51. Clark S, Long AA, Gaeta TJ, Camargo CA Jr. Multicenter study of emergency department visits for insect sting allergies. J Allergy Clin Immunol. 2005;116:643-9.

52. Clark S, Camargo CA Jr. Emergency treatment and prevention of insect-sting anaphylaxis. Curr Opin Allergy Clin Immunol. 2006;6:279-83.

53. Clark S, Boggs KM, Balekian DS, Hasegawa K, Vo P, Rowe BH, et al. Changes in emergency department concordance with guidelines for the management of stinging insect-induced anaphylaxis: 1999-2001 versus 2013-2015. Ann Allergy Asthma Immunol. 2018;120:419-23.

54. Lieberman P, Nicklas RA, Oppenheimer J, Kemp SF, Lang DM, Bernstein DI, et al. The diagnosis and management of anaphylaxis practice parameter: 2010 update. J Allergy Clin Immunol. 2010;126:477-80.

55. Kemp SF, Lockey RF, Simons FE; World Allergy Organization ad hoc Committee on Epinephrine in Anaphylaxis. Epinephrine: the drug of choice for anaphylaxis. A statement of the World Allergy Organization. Allergy 2008;63:1061-70.

56. Soar J, Pumphrey R, Cant A, Clarke S, Corbett A, Dawson P, et al. Emergency treatment of anaphylactic reactions--guidelines for healthcare providers. Resuscitation. 2008;77:157-69.

57. Bock SA, Muñoz-Furlong A, Sampson HA. Further fatalities caused by anaphylactic reactions to food, 2001-2006. J Allergy Clin Immunol. 2007;119:1016-8.

58. Simons FE, Sheikh A. Evidence-based management of anaphylaxis. Allergy. 2007;62:827-9.

59. Muraro A, Roberts G, Clark A, Eigenmann PA, Halken S, Lack $G$, et al. The management of anaphylaxis in childhood: position paper of the European academy of allergology and clinical immunology. Allergy. 2007;62:857-71.

60. Tse Y, Rylance G. Emergency management of anaphylaxis in children and young people: new guidance from the Resuscitation Council (UK). Arch Dis Child Educ Pract. 2009;94:97-101.

61. Brown SG. Cardiovascular aspects of anaphylaxis: implications for treatment and diagnosis. Curr Opin Allergy Clin Immunol. 2005;5:359-64.

62. Simons FE, Schatz M. Anaphylaxis during pregnancy. J Allergy Clin Immunol. 2012;130:597-606.

63. Cousins L. Fetal oxygenation, assessment of fetal well-being, and obstetric management of the pregnant patient with asthma. J Allergy Clin Immunol. 1999;103:S343-9.

64. Brown SG, Blackman KE, Stenlake V, Heddle RJ. Insect sting anaphylaxis; prospective evaluation of treatment with intravenous adrenaline and volume resuscitation. Emerg Med J. 2004;21:149-54.

65. Simons FE, Ardusso LR, Dimov V, Ebisawa M, El-Gamal YM, Lockey RF, et al. World Allergy Organization Anaphylaxis Guidelines: 2013 update of the evidence base. Int Arch Allergy Immunol. 2013;162:193-204.

66. Runge JW, Martinez JC, Caravati EM, Williamson SG, Hartsell SC. Histamine antagonists in the treatment of acute allergic reactions. Ann Emerg Med. 1992;21:237-42.

67. Sheikh A, Ten Broek V, Brown SG, Simons FE. H1-antihistamines for the treatment of anaphylaxis: Cochrane systematic review. Allergy. 2007;62:830-7.

68. Choo KJ, Simons FE, Sheikh A. Glucocorticoids for the treatment of anaphylaxis. Cochrane Database Syst Rev. 2012;4:CD007596.
69. Compton J. Use of glucagon in intractable allergic reactions and as an alternative to epinephrine: an interesting case review. J Emerg Nurs. 1997;23:45-7.

70. Zaloga GP, DeLacey W, Holmboe E, Chernow B. Glucagon reversal of hypotension in a case of anaphylactoid shock. Ann Intern Med. 1986;105:65-6.

71. Schummer C, Wirsing $M$, Schummer W. The pivotal role of vasopressin in refractory anaphylactic shock. Anesth Analg. 2008; 107:620-4.

72. Hussain AM, Yousuf B, Khan MA, Khan FH, Khan FA. Vasopressin for the management of catecholamine-resistant anaphylactic shock. Singapore Med J. 2008;49:e225-8.

73. Bonifazi F, Jutel M, Biló BM, Birnbaum J, Muller U; EAACl Interest Group on Insect Venom Hypersensitivity. Prevention and treatment of hymenoptera venom allergy: guidelines for clinical practice. Allergy. 2005;60:1459-70.

74. Bilò MB, Cichocka-Jarosz E, Pumphrey R, Oude-Elberink $J N$, Lange J, Jakob T, et al. Self-medication of anaphylactic reactions due to Hymenoptera stings-an EAACl Task Force Consensus Statement. Allergy. 2016;71:931-43.

75. Song TT, Nelson MR, Chang JH, Engler RJ, Chowdhury BA. Adequacy of the epinephrine autoinjector needle length in delivering epinephrine to the intramuscular tissues. Ann Allergy Asthma Immunol. 2005;94:539-42.

76. Tsai G, Kim L, Nevis IF, Dominic A, Potts R, Chiu J, et al. Auto-injector needle length may be inadequate to deliver epinephrine intramuscularly in women with confirmed food allergy. Allergy Asthma Clin Immunol. 2014;10:39.

77. Schwirtz A, Seeger H. Comparison of the robustness and functionality of three adrenaline auto-injectors. J Asthma Allergy. 2012;5:39-49.

78. Duvauchelle T, Robert P, Donazzolo Y, Loyau S, Orlandini B, Lehert $P$, et al. Bioavailability and Cardiovascular Effects of Adrenaline Administered by Anapen Autoinjector in Healthy Volunteers. J Allergy Clin Immunol Pract. 2017. doi: 10.1016/j. jaip.2017.09.021.

79. Halbrich M, Mack DP, Carr S, Watson W, Kim H. CSACI position statement: epinephrine auto-injectors and children $<15 \mathrm{~kg}$. Allergy Asthma Clin Immunol. 2015;11:20.

80. Simons FER, Gu X, Silver NA, Simons KJ. EpiPen Jr versus EpiPen in young children weighing 15 to $30 \mathrm{~kg}$ at risk for anaphylaxis. J Allergy Clin Immunol. 2002;109:171-5.

81. Oude Elberink JN, van der Heide S, Guyatt GH, Dubois AE. Analysis of the burden of treatment in patients receiving an EpiPen for yellow jacket anaphylaxis. J Allergy Clin Immunol. 2006;118:699-704.

82. Simons FE, Edwards ES, Read EJ Jr, Clark S, Liebelt EL. Voluntarily reported unintentional injections from epinephrine auto-injectors. J Allergy Clin Immunol. 2010;125:419-23.

83. Zanotti R, Lombardo C, Passalacqua G, Caimmi C, Bonifacio $\mathrm{M}$, De Matteis $\mathrm{G}$, et al. Clonal mast cell disorders in patients with severe Hymenoptera venom allergy and normal serum tryptase levels. J Allergy Clin Immunol. 2015;136:135-9.

84. Pucci S, D'Alò S, De Pasquale T, Illuminati I, Makri E, Incorvaia C. Risk of anaphylaxis in patients with large local reactions to hymenoptera stings: a retrospective and prospective study. Clin Mol Allergy. 2015;13:21.

85. Severino $M$, Bilò MB, Bignardi D, Cortellini G, Kosinska M, Nittner-Marszalska $M$, et al. History of large local reaction 
to hymenoptera stings: outcome of re-sting (preliminary data). EAACI Annual Congress Helsinki 2017. \#1308 - Oral presentation.

86. European MedicineAgency, 26 June 2015. EMA/411622/2015. Migliorati gli strumenti di formazione raccomandati per supportare i pazienti che utilizzano l'autoiniettore di adrenalina.

87. Golden DB, Moffitt J, Nicklas R, Freeman T, Graft DF, Reisman $R E$, et al. Stinging insect hypersensitivity: a practice parameter update 2011. J Allergy Clin Immunol. 2011;127:852-4.

88. Baker TW, Forester JP, Johnson ML, Stolfi A, Stahl MC. The HIT study: Hymenoptera Identification Test--how accurate are people at identifying stinging insects? Ann Allergy Asthma Immunol. 2014;113:267-70.

89. Sturm GJ, Kranzelbinder B, Schuster C, Sturm EM, Bokanovic D, Vollmann J, et al. Sensitization to Hymenoptera venoms is common, but systemic sting reactions are rare. J Allergy Clin Immunol. 2014;133:1635-43 e1.

90. Sturm GJ, Varga EM, Roberts G, Mosbech H, Bilò MB, Akdis CA, et al. EAACl Guidelines on Allergen Immunotherapy: Hymenoptera venom allergy. Allergy. 2018;73:744-64.

91. Goldberg A, Confino-Cohen R. Timing of venom skin tests and IgE determinations after insect sting anaphylaxis. J Allergy Clin Immunol. 1997;100:182-4.

92. Corallino M, Nico A, Kourtis G, Caiaffa MF, Macchia L. Skin testing technique and precision in stinging insect allergy. J Clin Nurs. 2007;16:1256-64.

93. Demoly P, Michel FB, Bousquet J. In vivo methods for study of allergy: skin tests, techniques and interpretation. In: Middleton $E$, Red CE et al, editors. Allergy, principles and practice. New York: Mosby Co, 1998:430-9.

94. Vos B, Koehler J, Mueller S, Stretz E, Rueff F, Jakob T. Spiking venom with rVes $v 5$ improves sensitivity of IgE detection in patients with allergy to Vespula venom. J Allergy Clin Immunol. 2013;131:1225-7.

95. Tracy JM, Khan, FS; Demain, JG. Insect anaphylaxis: where are we? The stinging facts 2012. Curr Opin Allergy Clin Immunol. 2012;12:400-5.

96. Pantera B, Hoffman DR, Carresi L, Cappugi G, Turillazzi S, Manao $G$, et al. Characterization of the major allergens purified from the venom of the paper wasp Polistes gallicus. Biochim Biophys Acta. 2003;1623:72-81.

97. Bilò MB, Bonifazi, F. Advances in Hymenoptera venom immunotherapy. Curr Opin Allergy Clin Immunol. 2007;7:56773.

98. Severino MG, Caruso B, Bonadonna P, Labardi D, Macchia $D$, Campi $P$, et al. Cross reactivity between European hornet and yellow jacket venoms. Eur Ann Allergy Clin Immunol. 2010;42:141-5.

99. Macchia D, Cortellini G, Mauro M, Meucci E, Quercia O, Manfredi $M$, et al. Vespa crabro immunotherapy versus Vespula-venom immunotherapy in Vespa crabro allergy: a comparison study in field re-stings. World Allergy Organization J. 2018;11:3-8.

100. Bonadonna P, Zanotti R, Müller U. Mastocytosis and insect venom allergy. Curr Opin Allergy Clin Immunol. 2010;10:34753.

101. González-de-Olano D, Alvarez-Twose I, Vega A, Orfao A, Escribano L. Venom immunotherapy in patients with mastocytosis and hymenoptera venom anaphylaxis. Immunotherapy. 2011;3:637-51.

102. Strohmeier B, Aberer W, Bokanovic D, Komericki P, Sturm GJ. Simultaneous intradermal testing with hymenoptera venoms is safe and more efficient than sequential testing. Allergy. 2013;68:542-4.

103. Matricardi PM, Kleine-Tebbe J, Hoffmann HJ, Valenta R, Hilger C, Hofmaier S, et al. EAACl Molecular Allergology User's Guide. Pediatr Allergy Immunol. 2016;27:1-250.

104. Alfaya Arias T, Soriano Gómis V, Soto Mera T, Vega Castro A, Vega Gutiérrez JM, Alonso Llamazares A, et al; Hymenoptera Allergy Committee of the SEAIC. Key Issues in Hymenoptera Venom Allergy: An Update. J Investig Allergol Clin Immunol. 2017; 27:19-31.

105. Müller UR, Johansen N, Petersen $A B$, Fromberg-Nielsen J, Haeberli G. Hymenoptera venom allergy: analysis of double positivity to honey bee and Vespula venom by estimation of $\mathrm{lgE}$ antibodies to species-specific major allergens Api $\mathrm{m} 1$ and Ves v5. Allergy. 2009;64:543-8.

106. Leimgruber $A$, Lantin JP, Frei PC. Comparison of two in vitro assays, RAST and CAP, when applied to the diagnosis of anaphylactic reactions to honeybee or yellow jacket venoms. Correlation with history and skin tests. Allergy. 1993;48:415-20.

107. Blank S, Seismann H, Michel Y, McIntyre M, Cifuentes L, Braren I, et al. Api m 10, a genuine A. mellifera venom allergen, is clinically relevant but underrepresented in therapeutic extracts. Allergy. 2011;66:1322-9.

108. Blank S, Bilò MB, Ollert M. Component-resolved diagnostics to direct in venom immunotherapy: Important steps towards precision medicine. Clin Exp Allergy. 2018;48:354-64.

109. Köhler J, Blank S, Müller S, Bantleon F, Frick M, Huss-Marp J, et al. Component resolution reveals additional major allergens in patients with honeybee venom allergy. J Allergy Clin Immunol. 2014;133:1383-9.

110. Ebo DG, Faber M, Sabato V, Leysen J, Bridts CH, De Clerck LS. Component- resolved diagnosis of wasp (yellow jacket) venom allergy. Clin Exp Allergy. 2013;43:255-61.

111. Jin C, Focke M, Leonard R, Jarisch R, Altmann F, Hemmer W. Reassessing the role of hyaluronidase in yellow jacket venom allergy. J Allergy Clin Immunol. 2010;125:184-90.

112. Caruso B, Bonadonna $P$, Severino MG, Manfredi M, Dama A, Schiappoli $M$, et al. Evaluation of the lgE cross-reactions among vespid venoms. A possible approach for the choice of immunotherapy. Allergy. 2007;62:561-4.

113. Perez-Riverol A, Fernandes LGR, Musacchio Lasa A, Dos Santos-Pinto JRA, Moitinho Abram D, Izuka Moraes GH, et al. Phospholipase A1-based cross-reactivity among venoms of clinically relevant Hymenoptera from Neotropical and temperate regions. Mol Immunol. 2018;93:87-93.

114. Monsalve RI, Vega A, Marqués L, Miranda A, Fernández J, Soriano $V$, et al. Component-resolved diagnosis of vespid venom-allergic individuals: phospholipases and antigen 5 s are necessary to identify Vespula or Polistes sensitization. Allergy. 2012;67:528-36

115. Caruso B, Bonadonna P, Bovo C, Melloni N, Lombardo C, Senna $G$, et al. Wasp venom allergy screening with recombinant allergen testing. Diagnostic performance of rPol d 5 and rVes v 5 for differentiating sensitization to Vespula and Polistes subspecies. Clin Chim Acta. 2016;453:170-3. 
116. Savi E, Peveri S, Makri E, Pravettoni V, Incorvaia C. Comparing the ability of molecular diagnosis and CAP-inhibition in identifying the really causative venom in patients with positive tests to Vespula and Polistes species. Clin Mol Allergy. 2016;14:3.

117. Schiener M, Hilger C, Eberlein B, Pascal M, Kuehn A, Revets D, et al. The high molecular weight dipeptidyl peptidase IV Pol $\mathrm{d} 3$ is a major allergen of Polistes dominula venom. Sci Rep. 2018;8:1318.

118. Blank S, Neu C, Hasche D, Bantleon Fl, Jakob T, Spillner E. Polistes species venom is devoid of carbohydrate-based crossreactivity and allows interference free diagnostics. J Allergy Clin Immunol. 2013;131:1239-42.

119. Eberlein B, Krischan L, Darsow U, Ollert M, Ring J. Double positivity to bee and wasp venom: improved diagnostic procedure by recombinant allergen-based IgE testing and basophil activation test including data about crossreactive carbohydrate determinants. J Allergy Clin Immunol. 2012;130:155-61

120. Sturm GJ, Bilò MB, Bonadonna P, Hemmer W, Caruso B, Bokanovic $D$, et al. Ves $\vee 5$ can establish the diagnosis in patients without detectable specific IgE to wasp venom and a possible north-south difference in Api $m 1$ sensitization in Europe. J Allergy Clin Immunol. 2012;130:817.

121. Korošec P, Šilar M, Eržen R, Čelesnik N, Bajrović N, Zidarn M, et al. Clinical routine utility of basophil activation testing for diagnosis of hymenoptera-allergic patients with emphasis on individuals with negative venom-specific lgE antibodies. Int Arch Allergy Immunol. 2013;161:363-8.

122. Balzer L, Pennino D, Blank S, Seismann H, Darsow U, Schnedler $M$, et al. Basophil activation test using recombinant allergens: highly specific diagnostic method complementing routine tests in wasp venom allergy. PLoS One. 2014;9:e108619.

123. Bonadonna P, Zanotti R, Melioli G, Antonini F, Romano I, Lenzi $L$, et al. The role of basophil activation test in special populations with mastocytosis and reactions to hymenoptera sting. Allergy. 2012;67:962-5.

124. Bidad K, Nawijn M, van Oosterhout AJ, van der Heide S, Oude Elberink JN. Basophil activation test in the diagnosis and monitoring of mastocytosis patients with wasp venom allergy on immunotherapy. Cytometry B Clin Cytom. 2014;86:18390.

125. Rietveld MJ, Schreurs MW, Gerth van Wijk R, van Daele PL, Hermans MA. The Basophil Activation Test is not a useful screening tool for hymenoptera venom-related anaphylaxis in patients with systemic mastocytosis. Int Arch Allergy Immunol. 2016;169:125-9.

126. González-de-Olano D, Alvarez-Twose I, Morgado JM, Esteban López MI, Vega Castro A, Díaz de Durana MD, et al. Evaluation of basophil activation in mastocytosis with Hymenoptera venom anaphylaxis. Cytometry B Clin Cytom. 2011;80:167-75.

127. Rueff F, Przybilla B, Muller U, Mosbech $H$. The sting challenge test in hymenoptera venom allergy. Position paper of the Subcommittee on Insect Venom Allergy of the European Academy of Allergology and Clinical Immunology. Allergy. 1996:51:216-25.

128. Bonadonna $P$, Bonifacio M, Lombardo C, Zanotti R. Hymenoptera Allergy and Mast Cell Activation Syndromes. Curr Allergy Asthma Rep. 2016;16:5.
129. Alvarez-Twose I, González-de-Olano D, Sánchez-Muñoz L, Matito A, Jara-Acevedo M, Teodosio C, et al. Validation of the REMA score for predicting mast cell clonality and systemic mastocytosis in patients with systemic mast cell activation symptoms. Int Arch Allergy Immunol. 2012;157:275-80.

130. Pastorello EA, Schroeder JW, Veronese SM, Pravettoni V, De Gasperi A, Cantoni $S$, et al. Two cases of elevate tryptase in abdominal aortic aneurysm. Eur Ann Allergy Clin Immunol. 2015; 47:58-61.

131. Golden DBK. Insect allergy in children. Curr Opin Allergy Clin Immunol. 2006;6:289-93.

132. Müller U, Thurnheer U, Patrizzi R, Spiess J, Hoigné R. Immunotherapy in bee sting hypersensitivity. Bee venom versus wholebody extract. Allergy. 1979;34:369-78.

133. Moffitt JE, Golden DB, Reisman RE, Lee R, Nicklas R, Freeman $T$, et al. Stinging insect hypersensitivity: a practice parameter update. J Allergy Clin Immunol. 2004;114:869-86.

134. Cirillo AG, Incorvaia C, Bonadonna P, Cirillo Al, Mauro M, Passalacqua $\mathrm{G}$, et al. Ipersensibilità al veleno degli imenotteri. Aggiornamento delle Linee Guida della società Italiana di allergologia e immunologia clinica. Giornale Italiano di Allergologia e Immunologia Clinica 2010;20:46-62.

135. Matsuoka T, Shamji MH, Durham SR. Allergen immunotherapy and tolerance. Allergol Int. 2013;62:403-13.

136. Cavkaytar O, Akdis CA, Akdis M. Modulation of immune responses by immunotherapy in allergic diseases. Curr Opin Pharmacol. 2014;17:30-7.

137. Soyka MB, van de Veen W, Holzmann D, Akdis M, Akdis CA. Scientific foundations of allergen-specific immunotherapy for allergic disease. Chest. 2014;146:1347-57.

138. Carballo I, Carballada F, Nuñez-Orjales R, Martín-Lázaro J, Vidal C, Gonzalez-Quintela A. Total and Honeybee VenomSpecific Serum IgG4 and IgE in Beekeepers. J Investig Allergol Clin Immunol. 2017;27:146-8.

139. Akdis CA, Akdis M, Blesken T, Wymann D, Alkan SS, Müller U, et al. Epitope-specific $T$ cell tolerance to phospholipase $A 2$ in bee venom immunotherapy and recovery by IL-2 and IL-15 in vitro. J Clin Invest. 1996;98:1676-83.

140. Jutel M, Pichler WJ, Skrbic D, Urwyler A, Dahinden C, Müller UR. Bee venom immunotherapy results in decrease of IL-4 and IL-5 and increase of IFN-gamma secretion in specific allergenstimulated T cell cultures. J Immunol. 1995;154:4187-94.

141. Bellinghausen I, Metz G, Enk AH, Christmann S, Knop J, Saloga J. Insect venom immunotherapy induces interleukin-10 production and a Th2-to-Th1 shift, and changes surface marker expression in venom-allergic subjects. Eur J Immunol. 1997;27:1131-9.

142. Patella V, Incorvaia C, Ricciardi L, Florio G, Saija A, Frati F, et al. The adhesion molecule ICAM-1 is overexpressed in patients with hymenoptera venom allergy and decreases after ultrarush venom immunotherapy. J Biol Regul Homeost Agents. 2011;25:465-8.

143. Riccio AM, Saverino D, Pesce G, Rogkakou A, Severino M, Bonadonna $P$, et al. Effects of different up-dosing regimens for hymenoptera venom immunotherapy on serum CTLA-4 and IL-10. PLoS One. 2012;7:e37980.

144. Cichocka-Jarosz E, Sanak M, Szczeklik A, Brzyski P, Pietrzyk JJ. Impact of Hymenoptera venom allergy and the effects of specific venom immunotherapy on mast cell metabolites in 
sensitized children. Ann Agric Environ Med. 2014;21:294301.

145. Novak N, Mete N, Bussmann C, Maintz L, Bieber T, Akdis M, et al. Early suppression of basophil activation during allergenspecific immunotherapy by histamine receptor 2. J Allergy Clin Immunol 2012;130:1153-8.

146. Akdis CA, Blesken $T$, Akdis M, Wüthrich B, Blaser K. Role of interleukin 10 in specific immunotherapy. J Clin Invest. 1998; 102:98-106

147. Akdis CA, Blaser K. IL-10-induced anergy in peripheral T cell and reactivation by microenvironmental cytokines: two key steps in specific immunotherapy. FASEB J. 1999;13:603-9.

148. van de Veen W, Stanic B, Yaman G, Wawrzyniak M, Söllner S, Akdis DG, et al. IgG4 production is confined to human IL-10producing regulatory $B$ cells that suppress antigen-specific immune responses. J Allergy Clin Immunol. 2013;131:120412.

149. Zhang $H$, Kong $H$, Zeng $X$, Guo L, Sun $X$, He S. Subsets of regulatory $T$ cells and their roles in allergy. J Transl Med. 2014; 12:125.

150. Aslam A, Chan H, Warrell DA, Misbah S, Ogg GS. Tracking antigen-specific T-cells during clinical tolerance induction in humans. PLoS One 2010;5:e11028.

151. Oude Elberink JO, De Monchy JGR, Van Der Heide S, Guyatt $\mathrm{GH}$, Dubois AEJ. Venom immunotherapy improves health related quality of life in patients allergic to yellow jacket venom. J Allergy Clin Immunol. 2002;110:174-82.

152. Niedoszytko $M$, de Monchy J, van Doormaal JJ, Jassem $E_{\text {, }}$ Oude Elberink JN. Mastocytosis and insect venom allergy: diagnosis, safety and efficacy of venom immunotherapy. Allergy. 2009:64:1237-45.

153. Graft DF, Schuberth KC, Kagey-Sobotka A, Kwiterovich KA, Niv $Y$, Lichtenstein LM, et al. A prospective study of the natural history of large local reactions after Hymenoptera stings in children. J Pediatr. 1984;104:664.

154. Golden DB, Kagey-Sobotka A, Norman PS, Hamilton RG, Lichtenstein LM. Outcomes of allergy to insect stings in children, with and without venom immunotherapy. $\mathrm{N}$ Engl J Med. 2004:351:668-74.

155. Golden DB, Kelly D, Hamilton RG, Craig TJ. Venom immunotherapy reduces large local reactions to insect stings. J Allergy Clin Immunol. 2009;123:1371-5.

156. Boyle RJ, Elremeli M, Hockenhull J, Cherry MG, Bulsara MK Daniels $\mathrm{M}$, et al. Venom immunotherapy for preventing allergic reactions to insect stings. Cochrane Database Syst Rev. 2012;10:CD008838.

157. Thurnheer U, Müller U, Stoller R, Lanner A, Hoigné R. Venom immunotherapy in hymenoptera sting allergy. Comparison of rush and conventional hyposensitization and observations during long-term treatment. Allergy. 1983;38:465-75.

158. Urbanek R, Forster J, Kuhn W, Ziupa J. Discontinuation of bee venom immunotherapy in children and adolescents. J Pediatr. 1985; 107:367-71.

159. Keating MU, Kagey-Sobotka A, Hamilton RG, Yunginger JW. Clinical and immunologic follow-up of patients who stop venom immunotherapy. J Allergy Clin Immunol. 1991;88:33948 .

160. Müller U, Helbling A, Berchtold E. Immunotherapy with honeybee venom and yellow jacket venom is different regarding efficacy and safety. J Allergy Clin Immunol. 1992:89:529-35.

161. Quercia O, Emiliani F, Pecora S, Burastero SE, Stefanini GF. Efficacy, safety, and modulation of immunologic markers by immunotherapy with honeybee venom: comparison of standardized quality depot versus aqueous extract. Allergy Asthma Proc. 2006:27:151-8.

162. Goldberg A, Confino-Cohen R. Bee venom immunotherapy how early is it effective? Allergy. 2010;65:391-5.

163. Patella V, Florio G, Giuliano A, Oricchio C, Spadaro G, Marone $\mathrm{G}$, et al. Hymenoptera Venom Immunotherapy: tolerance and efficacy of an ultrarush protocol versus a rush and a slow conventional Ppotocol. J Allergy (Cairo). 2012; 2012:192192.

164. Ruëff F, Przybilla B, Biló MB, Müller U, Scheipl F, Seitz $M J$, et al. Clinical effectiveness of hymenoptera venom immunotherapy: a prospective observational multicenter study of the European Academy of Allergology and Clinical Immunology interest group on insect venom hypersensitivity. PLoS One.2013;8:e63233.

165. Stritzke Al, Eng PA. Age-dependent sting recurrence and outcome in immunotherapy-treated children with anaphylaxis to Hymenoptera venom. Clin Exp Allergy. 2013; 43:950-5.

166. Ruëff F, Vos B, Oude Elberink J, Bender A, Chatelain R, DugasBreit $S$, et al. Predictors of clinical effectiveness of Hymenoptera venom immunotherapy. Clin Exp Allergy. 2014;44:736-46.

167. Münstedt K, Wrobel D, Kalder M. Efficacy of venom immunotherapy in beekeepers. I Investig Allergol Clin Immunol. 2010:20:58-62.

168. Bilò MB, Antonicelli L, Bonifazi F. Purified vs. nonpurified venom immunotherapy. Curr Opin Allergy Clin Immunol. 2010; 10:330-6

169. Bonadonna P, Caruso B, Labardi D, Dama A, Senna G, Passalacqua $\mathrm{G}$. Treatment with American Polistes venom was ineffective in an Italian patient allergic to European Polistes. Allergy. 2007:62:966-7.

170. Savi E, Incorvaia C, Boni E, Mauro M, Peveri S, Pravettoni V, et al. Which immunotherapy product is better for patients allergic to Polistes venom? A laboratory and clinical study. PlosOne 2017:12:e0180270.

171. Golden DB, Tracy JM, Freeman TM, Hoffman DR; Insect Committee of the American Academy of Allergy Asthma and Immunology. Negative venom skin test results in patients with histories of systemic reaction to a sting. J Allergy Clin Immunol. 2003;112:495-8.

172. Gutiérrez Fernández D, Moreno-Ancillo A, Fernández Meléndez S, Domínguez-Noche C, Gálvez Ruiz P, Alfaya Arias $T$, et al. Insect venom immunotherapy: analysis of the safety and tolerance of 3 build-up protocols frequently used in Spain. J Investig Allergol Clin Immunol. 2016;26:366-73.

173. Gillman SA, Cummins LH, Kozak PP, Hoffman DR. Venom immunotherapy: comparison of "rush" vs "conventional" schedules. Ann Allergy. 1980:45:351-4.

174. Thurnheer U, Müller U, Stoller R, Lanner A, Hoigné R. Venom immunotherapy in hymenoptera sting allergy. Comparison of rush and conventional hyposensitization and observations during long-term treatment. Allergy. 1983;38:465-75.

175. Rosman $Y$, Confino-Cohen $R$, Goldberg $A$. Venom Immunotherapy in High-Risk Patients: The Advantage of 
the Rush Build-Up Protocol. Int Arch Allergy Immunol. 2017; 174:45-51.

176. Schiavino D, Nucera E, Pollastrini E, De Pasquale T, Buonomo $A$, Bartolozzi $F$, et al. Specific ultrarush desensitization in Hymenoptera venom-allergic patients. Ann Allergy Asthma Immunol. 2004;92:409-13.

177. Alessandrini AE, Berra D, Rizzini FL, Mauro M, Melchiorre $A$, Rossi $F_{\text {, et }}$ al. Flexible approaches in the design of subcutaneous immunotherapy protocols for Hymenoptera venom allergy. Ann Allergy Asthma Immunol. 2006;97:92-7.

178. Roumana A, Pitsios C, Vartholomaios S, Kompoti E, KontouFili K. The safety of initiating Hymenoptera immunotherapy at 1 microg of venom extract. J Allergy Clin Immunol. 2009:124:379-81.

179. Ruëff F, Wenderoth A, Przybilla B. Patients still reacting to a sting challenge while receiving conventional Hymenoptera venom immunotherapy are protected by increased venom doses. J Allergy Clin Immunol. 2001;108:1027-32

180. Gadde J, Sobokta A, Valentine M, Lichtenstein L, Golden D. Intervals of six and eight weeks in maintenance venom immunotherapy. Ann Allergy. 1985;54:348.

181. Simioni L, Vianello A, Bonadonna P, Marcer G, Severino M, Pagani $M$, et al. Efficacy of venom immunotherapy given every 3 or 4 months: a prospective comparison with the conventional regimen. Ann Allergy Asthma Immunol. 2013;110:51-4.

182. Cavallucci E, Ramondo S, Renzetti A, Turi MC, Di Claudio $F$, Braga $M$, et al. Maintenance venom immunotherapy administered at a 3-month interval preserves safety and efficacy and improves adherence. J Investig Allergol Clin Immunol. 2010;20:63-8.

183. Goldberg A, Confino-Cohen R. Effectiveness of maintenance bee venom immunotherapy administered at 6-month intervals. Ann Allergy Asthma Immunol. 2007;99:352-7.

184. Michalke B, Kramer MF, Brehler R. Aluminium (Al) speciation in serum and urine after subcutaneous venom immunotherapy with Al as adjuvant. J Trace Elem Med Biol. 2018;21:doi:10.1016/j.jtemb.2018.02.014.

185. Bilò MB, Martini M, Berra D, Scarpa A, Losappio L, Quercia $O$, et al. Hymenoptera venom immunotherapy: how to safely switch to the same venom of a different manufacturer. J Investig Allergol Clin Immunol 2018;28:205-8.

186. Ridolo E, Martignago I, Passalacqua G, Mauro M, Incorvaia C. Evaluation of the safety of a protocol for switching venom immunotherapy products. Ann Allergy Asthma Immunol. 2018; 120:429-30.

187. Müller UR, Ring J. When can Immunotherapy for Insect Sting Allergy Be Stopped? J Allergy Clin Immunol Pract. 2015;3:32428.

188. Golden DB, Johnson K, Addison BI, Valentine MD, KageySobotka A, Lichtenstein LM. Clinical and immunologic observations in patients who stop venom immunotherapy. J Allergy Clin Immunol. 1986;77:435-42.

189. Lerch E, Müller UR. Long-term protection after stopping venom immunotherapy: results of re-stings in 200 patients. J Allergy Clin Immunol. 1998;101:606-12.

190. von Moos S, Graf N, Johansen P, Müllner G, Kündig TM, Senti G. Risk assessment of Hymenoptera re-sting frequency: implications for decision-making in venom immunotherapy. Int Arch Allergy Immunol. 2013;160:86-92.
191. Müller U, Berchtold E, Helbling A. Honeybee venom allergy: results of a sting challenge 1 year after stopping successful venom immunotherapy in 86 patients. J Allergy Clin Immunol. 1991; 87:702-9.

192. Haugaard L, Nørregaard OF, Dahl R. In-hospital sting challenge in insect venom-allergic patients after stopping venom immunotherapy. J Allergy Clin Immunol. 1991;87:699-702.

193. van Halteren HK, van der Linden PW, Burgers JA, Bartelink AK. Discontinuation of yellow jacket venom immunotherapy: follow-up of 75 patients by means of deliberate sting challenge. J Allergy Clin Immunol. 1997;100:767-70.

194. Golden DB, Addison BJ, Gadde J, Kagey Sobotka A, Lichtenstein LM. Prospective observations on stopping prolonged venom immunotherapy. J Allergy Clin Immunol. 1989;84:162-7.

195. Golden DB, Kwiterovich KA, Kagey-Sobotka A, Valentine MD, Lichtenstein LM. Discontinuing venom immunotherapy: outcome after five years. J Allergy Clin Immunol. 1996;97:579-87.

196. Pravettoni V, Piantanida M, Primavesi L, Forti S, Pastorello EA. Determinants of venom-specific lgE antibody concentration during long-term wasp venom immunotherapy. Clin Mol Allergy. 2015;13:29.

197. Saulite I, Hoetzenecker W, Guenova E, Schmid-Grendelmeier $\mathrm{P}$, Glatz M. Skin test reactivity to hymenoptera venom after venom immunotherapy correlates inversely with the $\mathrm{gG} / \mathrm{ggE}$ ratio. Int Arch Allergy Immunol. 2017;174:190-9.

198. Arzt L, Bokanovic D, Schrautzer C, Laipold K, Möbs C, Pfützner $W$, et al. Immunological differences between insect venom-allergic patients with and without immunotherapy and asymptomatically sensitized subjects. Allergy. 2017; doi: 10.1111/all.13368.

199. van der Linden PW, Hack CE, Struyvenberg A, van der Zwan JK. Insect-sting challenge in 324 subjects with a previous anaphylactic reaction: current criteria for insect-venom hypersensitivity do not predict the occurrence and the severity of anaphylaxis. J Allergy Clin Immunol. 1994;94:151-9.

200. Cortellini G, Severino M, Francescato E, Turillazzi S, Spadolini I, Rogkakou A, et al. Evaluation and validation of a bee venom sting challenge performed by a micro-syringe. Ann Allergy Asthma Immunol. 2012;109:438-41.

201. Oude Elberink JN, de Monchy JG, Kors JW, van Doormaal JJ, Dubois AE. Fatal anaphylaxis after a yellow jacket sting, despite venom immunotherapy, in two patients with mastocytosis. J Allergy Clin Immunol. 1997;99:153-4.

202. Wagner N, Fritze D, Przybilla B, Hagedorn M, Ruëff F. Fatal anaphylactic sting reaction in a patient with mastocytosis. Int Arch Allergy Immunol. 2008;146:162-3.

203. Bonadonna P, Zanotti R, Pagani M, Bonifacio M, Scaffidi L, Olivieri E, et al. Anaphylactic Reactions After Discontinuation of Hymenoptera Venom Immunotherapy: A Clonal Mast Cell Disorder Should Be Suspected. J Allergy Clin Immunol Pract. 2017; doi: 10.1016/j.jaip.2017.11.025.

204. Mosbech H, Müller U. Side-effects of insect venom immunotherapy: results from an EAACl multicenter study. Allergy. 2000;55:1005-10.

205. Pasaoglu G, Sin BA, Misirligil Z. Rush hymenoptera venom immunotherapy is efficacious and safe. I Investig Allergol Clin Immunol. 2006;16:232-8 
206. Park JH, Yim BK, Lee J-H, Lee S, Kim T-H. Risk associated with bee venom therapy: a systematic review and meta-analysis. PLoS One. 2015;10:e0126971.

207. Ruëff F, Przybilla B, Biló MB, Müller U, Scheipl F, Aberer W, et al. Predictors of side effects during the buildup phase of venom immunotherapy for Hymenoptera venom allergy: the importance of baseline serum tryptase. J Allergy Clin Immunol. 2010;126:105-11.

208. Brockow K, Jofer C, Behrendt H, Ring J.Anaphylaxis in patients with mastocytosis: a study on history, clinical features and risk factors in 120 patients. Allergy. 2008;63:226-32

209. Brehler R, Wolf $H$, Kütting $B$, Schnitker J, Luger T. Safety of a two-day ultrarush insect venom immunotherapy protocol in comparison with protocols of longer duration and involving a larger number of injections. J Allergy Clin Immunol. 2000;105:1231-5.

210. Stoevesandt J, Hosp C, Kerstan A, Trautmann A. Risk stratification of systemic allergic reactions during Hymenoptera venom immunotherapy build-up phase. J Dtsch Dermatol Ges. 2014; $12: 244-56$

211. Bilò MB, Corsi A, Agolini S, Tontini C, Antonicelli L. Safety of a two-day ultra-rush immunotherapy in vespid allergic patients: focus on elevated serum tryptase. Ann Allergy Asthma Immunol. 2018 Mar 22. pii: S1081-1206(18)30219-9.

212. Quercia O, Rafanelli S, Puccinelli P, Stefanini GF. The safety of cluster immunotherapy with aluminium hydroxide-adsorbed honey bee venom extract. J Investig Allergol Clin Immunol. 2001;11:27-33

213. Cadario G, Marengo F, Ranghino E, Rossi R, Gatti B, Cantone R, et al. Higher frequency of early local side effects with aqueous versus depot immunotherapy for hymenoptera venom allergy. J Investig Allergol Clin Immunol. 2004;14:127-33.

214. Incorvaia C, Frati F, Dell'Albani I, Robino A, Cattaneo E, Mauro M, et al. Safety of hymenoptera venom immunotherapy: a systematic review. Expert Opin Pharmacother. 2011;12:2527-32.

215. Bilò MB, Severino M, Cilia M, Pio A, Casino G, Ferrarini E, et al. The VISYT trial: Venom immunotherapy safety and tolerability with purified vs nonpurified extracts. Ann Allergy Asthma Immunol. 2009;103:57-61.

216. Bilò $M B$, Cinti $B$, Brianzoni $M F$, Braschi $M C$, Bonifazi $M$, Antonicelli L. Honeybee venom immunotherapy: a comparative study using purified and nonpurified aqueous extracts in patients with normal Basal serum tryptase concentrations. J Allergy (Cairo). 2012;2012:869243.

217. Müller U, Hari Y, Berchtold E. Premedication with antihistamines may enhance efficacy of specific allergen immunotherapy. J Allergy Clin Immunol. 2001;107:81-6.

218. Müller UR, Jutel $M$, Reimers $A$, Zumkehr J, Huber $C$ Kriegel $C$, et al. Clinical and immunologic effects of $\mathrm{H} 1$ antihistamine preventive medication during honeybee venom immunotherapy. J Allergy Clin Immunol. 2008;122:1001-7.

219. Stoevesandt J, Hofmann B, Hain J, Kerstan A, Trautmann A. Single venom-based immunotherapy effectively protects patients with double positive tests to honey bee and Vespula venom. Allergy Asthma Clin Immunol. 2013;9:33.

220. Gastaminza G, Algorta J, Audicana M, Etxenagusia M, Fernandez E, Munoz D. Systemic reactions to immunotherapy: influence of composition and manufacturer. Clin Exp Allergy. 2003;33:470-4.
221. Boni E, Incorvaia C, Mauro M. Dose-dependence of protection from systemic reactions to venom immunotherapy by omalizumab. Clin Mol Allergy. 2016;14:14.

222. Ricciardi L. Omalizumab: A useful tool for inducing tolerance to bee venom immunotherapy. Int J Immunopathol Pharmacol. 2016:29:726-8

223. Metzger WJ, Turner E. The safety of immunotherapy during pregnancy. J Allergy Clin limmunol. 1978;61:268-72.

224. Schwartz HJ, Golden DBK, Lockey RF. Venom immunotherapy in the Hymenoptera-allergic pregnant patient. J Allergy Clin Immunol. 1990;85:709-12.

225. Hill JA, Choi BC. Maternal immunological aspects of pregnancy success and failure. J Reprod Fertil Suppl. 2000;47:91-7.

226. Markert UR, Arck PC, Peiker G, Mock BA. Might wasp venom desensitization induced Th2 to Th1 shift cause pregnancy failure? Am J Reprod Immunol. 2002;47:193-5.

227. Sills ES, Conway SC, Kaplan CR, Perloe M, Tucker MJ. First successful case of in vitro fertilization-embryo transfer with venom immunotherapy for hymenoptera sting allergy. Clin Mol Allergy. 2004:2:11.

228. Pitsios C, Demoly P, Bilò MB, Gerth van Wijk R, Pfaar O, Sturm GJ, et al. Clinical contraindications to allergen immunotherapy: an EAACI position paper. Allergy. 2015;70:897-909.

229. Kiel MA, Roder E, Gerth van Wijk R, Al MJ, Hop WC, Rutten-van Molken MP. Real-life compliance and persistence among users of subcutaneous and sublingual allergen immunotherapy. J Allergy Clin Immunol. 2013;132:353-60.

230. Bilò MB, Kamberi $E$, Tontini $C$, Marinangeli L, Cognigni $M$, Brianzoni MF, et al. High adherence to hymenoptera venom subcutaneous immunotherapy over a 5-year follow-up: A reallife experience. J Allergy Clin Immunol Pract. 2016;4:327-9.

231. Ross RN, Nelson HS, Finegold I. Effectiveness of specific immunotherapy in the treatment of Hymenoptera venom hypersensitivity: A meta-analysis. Clin Ther. 2000;22:351-8.

232. Muller U, Mosbech H. Position paper: Immunotherapy with hymenoptera venoms. (EAACI) The European Academy of Allergology and Clinical Immunology. Allergy. 1993;48:3746.

233. Dhami S, Nurmatov U, Varga EM, Sturm G, Muraro A, Akdis $C A$, et al. Allergen immunotherapy for insect venom allergy: protocol for a systematic review. Clin Transl Allergy. 2016;6:6.

234. Lange J, Cichocka-Jarosz E, Marczak H, Krauze A, Tarczoń I, Świebocka $E$, et al. Natural history of Hymenoptera venom allergy in children not treated with immunotherapy. Ann Allergy Asthma Immunol. 2016;116:225-9.

235. Graft DF, Schuberth KC, Kagey-Sobotka A, Kwiterovich $K A$, Niv $Y$, Lichtenstein LM, et al. Assessment of prolonged venom immunotherapy in children. J Allergy Clin Immunol. 1987:80:162-9

236. Steiss JO, Jodicke B, Lindemann H. Modified ultrarush insect VIT protocol for children. Ann Asthma Proc. 2006;27:148-50

237. Stoevesandt J, Hosp C, Kerstan A, Trautmann A. Safety of 100 $\mu \mathrm{g}$ venom immunotherapy rush protocols in children compared to adults. Allergy Asthma Clin Immunol. 2017;13:32.

238. Confino-Cohen R, Rosman Y, Goldberg A. Rush Venom Immunotherapy in Children. J Allergy Clin Immunol Pract. 2017;5:799-803.

239. Nittner-Marszalska M, Cichocka-Jarosz E, Małaczyńska T, Kraluk B, Rosiek-Biegus M, Kosińska M, et al. Safety of ultrarush 
venom immunotherapy: comparison between children and adults. J Investig Allergol Clin Immunol. 2016;26:40-7.

240. Birnbaum J, Ramadour M, Magna A, Vervloet D. Hymenoptera ultra-rush venom immunotherapy (210 min): a safety study and risk factors. Clin Exp Allergy. 2003;33:58-64.

241. Golden DB, Kagey-Sobotka A, Lichtenstein LM. Survey of patients after discontinuing venom immunotherapy. J Allergy Clin Immunol 2000;105:385-90.

242. Fiedler C, Miehe U, Treudler R, Kiess W, Prenzel F. Longterm follow-up of children after venom immunotherapy: low adherence to anaphylaxis guidelines. Int Arch Allergy Immunol. 2017;172:167-72.

243. Marone G, Patella V, de Crescenzo G, Genovese A, Adt M. Human heart mast cells in anaphylaxis and cardiovascular disease. Int Arch Allergy Immunol. 1995;107:72-5.

244. Marone G, Genovese A, Varricchi G, Granata F. Human heart as shock organ in anaphylaxis. Allergo J Int. 2014;23:60-6.

245. Kogias JS, Sideris SK, Anifadia SK. Kounis syndrome associated with hypersensitivity to hymenoptera stings. Int J Cardiol. 2007;114:252-5.

246. Bach MK. Mediators of anaphylaxis and inflammation. Annu Rev. 1982;36:371-413.

247. Quercia O, Emiliani F, Foschi FG, Stefanini GF. Ventricular fibrillation after a hymenoptera sting. Int J Cardiol. 2008;127:e5-7.

248. White JL, Greger KC, Lee S, Kahoud RJ, Li JT, Lohse CM, Campbell RL. Patients taking $\beta$-Blockers do not require increased doses of epinephrine for anaphylaxis. J Allergy Clin Immunol Pract. 2018;13: pii: S2213-2198(18)30005-9

249. Wohrl S, Kinaciyan T, Jalili A, Stingl G, Moritz KB. Malignancy and specific allergen immunotherapy: the results of a case series. Int Arch Allergy Immunol. 2011;156:313-9.

250. Aeberhard J, Haeberli G, Müller UR, Helbling A. Specific immunotherapy in hymenoptera venom allergy and concomitant malignancy: a retrospective follow-up focusing on effectiveness and safety. J Investig Allergol Clin Immunol. 2017; 27:370-7.

251. Pfaar O, Bachert C, Bufe A, Buhl R, Ebner C, Eng P, et al. Guideline on allergen-specific immunotherapy in $\mathrm{IgE}$ mediated allergic diseases: S2k Guideline of the German Society for Allergology and Clinical Immunology (DGAKI), the Society for Pediatric Allergy and Environmental Medicine (GPA), the Medical Association of German Allergologists (AeDA), the Austrian Society for Allergy and Immunology (OGAI), the Swiss Society for Allergy and Immunology (SGAI), the German Society of Dermatology (DDG), the German Society of Oto- Rhino-Laryngology, Head and Neck Surgery (DGHNO-KHC), the German Society of Pediatrics and Adolescent Medicine (DGKJ), the Society for Pediatric Pneumology (GPP), the German Respiratory Society (DGP), the German Association of ENT Surgeons (BV-HNO), the Professional Federation of Paediatricians and Youth Doctors (BVKJ), the Federal Association of Pulmonologists (BDP) and the German Dermatologists Association (BVDD). Allergol J Int. 2014;23:282-319.

252. Bonadonna P, Lombardo C, Zanotti R. Mastocytosis and Allergic Diseases. J Investig Allergol Clin Immunol. 2014;24:288-97.

253. Alvarez-Twose I, Zanotti R, González-de-Olano D, Bonadonna P, Vega A, Matito A, et al. Nonaggressive systemic mastocytosis
(SM) without skin lesions associated with insect-induced anaphylaxis shows unique features versus other indolent SM. J Allergy Clin Immunol. 2014;133:520-8.

254. Van Anrooij B, van der Veer $E$, de Monchy JG, van der Heide S, Kluin-Nelemans JC, van Voorst Vader PC, et al. Higher mast cell load decreases the risk of Hymenoptera venom-induced anaphylaxis in patients with mastocytosis. J Allergy Clin Immunol. 2013;132:125-30.

255. Bonadonna P, Gonzalez-de-Olano D, Zanotti R, Riccio A, De Ferrari L, Lombardo C, et al. Venom immunotherapy in patients with clonal mast cell disorders: efficacy, safety, and practical considerations. J Allergy Clin Immunol Pract. 2013;1:474-8.

256. Bonadonna P, Zanotti R, Caruso B, Castellani L, Perbellini O, Colarossi $S$, et al. Allergen specific immunotherapy is safe and effective in patients with systemic mastocytosis and hymenoptera allergy. J Allergy Clin Immunol. 2008;121:2567 .

257. Siracusa A, Folletti I, Gerth van Wijk R, Jeebhay F, Moscato G, Quirce $S$, et al. Occupational anapylaxis - an EAACI task force consensus statement. Allergy. 2015;70:141-52.

258. Hayashi $Y$, Hirata $H$, Watanabe M, Yoshida N, Yokoyama $T$, Murayama $Y$, et al. Epidemiologic investigation of hornet and paper wasp sting in forest workers and electrical facility field workers in Japan. Allergol Int. 2014;63:21-6.

259. Bonadonna P, Schiappoli M, Dama A, Olivieri M, Perbellini L, Senna $G$, et al. Is hymenoptera venom allergy an occupational disease? Occup Environ Med. 2008; 65:217-8.

260. Cruz S, Vega A, Fernández S, Marquès L, Baltasar M, Alonso $A$, et al. Report from the Hymenoptera Committee of the Spanish Society of Allergology and Clinical Immunology: immunotherapy with bumblebee venom. J Investig Allergol Clin Immunol. 2012;22:377-8.

261. Toletone A, Voltolini S, Passalacqua G, Dini G, Bignardi D, Minale $P$, et al. Hymenoptera venom allergy in outdoor workers: occupational exposure, clinical features and effects of allergen immunotherapy. Hum Vaccin Immunother. 2017;13:477-83.

262. Ruëff F, Chatelain R, Przybilla B. Management of occupational Hymenoptera allergy. Curr Opin Allergy Clin Immunol. 2011;11:69-74.

263. Paolocci G, Folletti I, Torén K, Muzi G, Murgia N. Hymenoptera venom allergy: work disability and occupational impact of venom immunotherapy. BMJ Open. 2014;4:e005593.

264. Oude Elberink JN. Significance and rationale of studies of health-related quality of life in anaphylactic disorders. Curr Opin Allergy Clin Immunol. 2006;6:298-302.

265. Alfaya T, Vega A, Domínguez-Noche $C$, Ruiz B, Marqués $L$, Sánchez-Morillas L. Longitudinal Validation of the Spanish Version of the Health-Related Quality of Life Questionnaire for Hymenoptera Venom Allergy (HRQLHA). J Investig Allergol Clin Immunol. 2015;25:426-30.

266. Armisén M, Guspi R, Alfaya T, Cruz S, Fernández S, DomínguezNoche $C$, et al. Cross-sectional validation of a quality of life questionnaire in Spanish for patients allergic to hymenoptera venom. J Investig Allergol Clin Immunol. 2015;25:176-82.

267. Dubois AEJ. Venom immunotherapy improves health-related quality of life in patients allergic to yellow jacket venom. J Allergy Clin Immunol. 2002;110:174-82.

268. Koschel DS, Schmies M, Weber CN, Höffken G, Balck F. Tolerated sting challenge in patients on Hymenoptera venom 
immunotherapy improves health-related quality of life. J Investig Allergol Clin Immunol. 2014;24:226-30.

269. Brzyski P, Cichocka-Jarosz E, Lis G, Tobiasz-Adamczyk B. Development of Parents' of Children with Hymenoptera Venom Allergy Quality of Life Scale (PoCHVAQoLS). Postepy Dermatol Alergol. 2015;32:143-53.

270. Severino MG, Cortellini G, Bonadonna P, Francescato E, Panzini I, Macchia D, et al. Sublingual immunotherapy for large local reactions caused by honeybee sting: a double-blind, placebocontrolled trial. J Allergy Clin Immunol. 2008;122:44-8.

271. Golden DB, Kwiterovich KA, Kagey-Sobotka A, Lichtenstein LM. Discontinuing venom immunotherapy: extended observations. J Allergy Clin Immunol. 1998;101:298-305.

272. Hoffman DR. Fatal reactions to hymenoptera stings. Allergy Asthma Proc. 2003;24:123-7.

273. Reisman RE. Duration of venom immunotherapy: relationship to the severity of symptoms of initial insect sting anaphylaxis. J Allergy Clin Immunol. 1993;92:831-6.

274. Cichocka-Jarosz E, Sanak M, Szczeklik A, Brzyski P, Gielicz A, Pietrzyk JJ. Serum tryptase level is a better predictor of systemic side effects than prostaglandin D2 metabolites during venom immunotherapy in children. J Investig Allergol Clin Immunol. 2011;21:260-9.
275. González de Olano D, Alvarez-Twose I, Esteban-López MI, Sánchez-Muñoz L, de Durana MD, Vega A, et al. Safety and effectiveness of immunotherapy in patients with indolent systemic mastocytosis presenting with Hymenoptera venom anaphylaxis. J Allergy Clin Immunol. 2008;121:519-26.

276. Muller UR. Insect sting allergy. Clinical picture, diagnosis and treatment. Stuttgard/New York: Gustav Fisher Verlag 1990.

Manuscript received May 5, 2018; accepted for publication August 23, 2018.

\section{- Maria Beatrice Bilò}

Allergy Unit

Department of Internal Medicine

University Hospital of Ancona

Via Conca 71

60126 Ancona, Italy

E-mail: MariaBeatrice.Bilo@ospedaliriuniti.marche.it 